\title{
Optimal exergy-based control of internal combustion engines
}

\author{
M. Razmara*a, M. Bidarvatan ${ }^{\mathrm{a}}$, M. Shahbakhti ${ }^{\mathrm{a}}$, R.D. Robinett III ${ }^{\mathrm{a}}$ \\ ${ }^{a}$ Mechanical Engineering-Engineering Mechanics, Michigan Technological University, \\ Houghton, MI, USA 49931
}

\begin{abstract}
Exergy or availability is defined as the maximum useful work during a process. This metric has been used to analyze and understand loss mechanisms of Internal Combustion Engines (ICEs). In this paper, an optimal control method based on exergy is introduced for transient and steady state operation of ICEs. First, an exergy model is developed for a single cylinder Ricardo engine. The ICE exergy model is based on the Second Law of Thermodynamics (SLT) and characterizes irreversibilities. Such quantifications are not identified in the First Law of Thermodynamics (FLT) analysis. For steady-state operation of the ICE, a set of 175 different operating conditions is used to construct the SLT efficiency maps. Two different SLT efficiency maps are generated depending on the applications whether work, or Combined Power and Exhaust Exergy (CPEX) is the desired output. To include transient ICE operation, a model to predict exergy loss/destruction during engine transients is developed. The sources of exergy destruction/loss are identified for a Homogeneous Charge Compression Ignition (HCCI) engine. Based on the engine operating conditions (i.e., steady-state or transient) SLT efficiency contour maps or predicted exergy losses are determined at every given engine load. An optimization algorithm is proposed to find the optimum combustion phasing to maximize the SLT efficiency. Application of the optimization algorithm is illustrated for combustion phasing control. The results show that using the exergy-based optimal control strategy leads to an average of $6.7 \%$ fuel saving and $8.3 \%$ exergy saving compared to commonly used FLT based combustion control in which a fixed combustion phasing (e.g., $8^{\circ} a T D C$ ) is used.
\end{abstract}

Keywords: Exergy-based control, Engine efficiency, Combustion phasing, Engine control

\footnotetext{
*Corresponding author

Email addresses: mrazmara@mtu.edu (M. Razmara*), mbidarva@mtu.edu (M. Bidarvatan), mahdish@mtu.edu (M. Shahbakhti), rdrobine@mtu.edu (R.D. Robinett III)
} 
2

\section{Introduction}

The First Law of Thermodynamics (FLT) deals with energy conservation whereas the Second Law of Thermodynamics (SLT) focuses on entropy production and irreversibilities in processes which cause deficiency. SLT states that energy has quality in addition to its quantity. Exergy or availability is the portion of energy that can do work in a specific environment. Exergy is based on FLT and SLT and determines the ability of a system to do work in a specific environment [1]. Exergy can be destroyed through irreversible processes including combustion, heat transfer, friction and mixing in Internal Combustion Engines (ICEs), unlike energy which is neither created nor destroyed. Irreversibilities lead to the loss of work potential during a process. For instance, exergy destruction of the combustion process in ICEs reduces the fuel potential to do mechanical work. Thus, identification of sources of exergy destruction in an ICE is crucial to enhance the engine performance and efficiency. SLT characterizes and quantifies the sources of irreversibility and exergy loss in ICEs.

FLT analysis does not recognize irreversibilities across systems' components, thus it provides limited insight for ICE optimal control. A large number of studies $[2,3,4,5,6,7,8,9,10,11,12,13,14]$ have analyzed SLT in ICEs. Figure 1 illustrates a summary of the ICE studies in the literature based on the exergy and SLT. As shown in Figure 1, depending on the use of exergy in ICEs, studies can be categorized into three main groups: (i) system analysis, (ii) design optimization, and (iii) controls. The first group consists of exergy analysis for (a) whole engine $[2,3,4,5]$, (b) combustion phasing [6, 7], (c) closed engine cycle [8, 9, 10, 13], (d) combustion process $[15,11,16]$, and (e) exhaust heat recovery $[17,18,19]$. For instance in [3], application of the SLT and its equations have been provided for different types of internal combustion engines and their subsystems (e.g., turbocharger, inlet and exhaust manifolds). Exergy analysis of a gasoline-fueled Homogeneous Charge Compression Ignition (HCCI) engine has been studied in [6]. According to the results in [6], the main exergy loss mechanism is combustion, which accounts for 19-23\% of total exergy loss. The other exergy loss mechanisms including heat loss, exhaust gases, and Unburnt Hydrocarbons (UHC) are responsible for 5-15\%, 12-20\%, and $1 \%$, respectively [6].

In [9], the effects of the air-fuel mixture properties on the exergy balance in the closed part of the engine cycle have been investigated for a Spark Ignition (SI) engine. They found that a slightly lean in-cylinder mixture leads to the best FLT and SLT efficiencies for SI engines. The effects of equivalence ratio, combustion temperature, in-cylinder pressure have been studied by Caton in [11]. The author in [11] 
concluded that the combustion irreversibilities are inversely related to the equivalence ratio. In addition, a higher combustion temperature leads to lower combustion irreversibilities and finally, the effect of changes of the combustion pressure on the exergy loss/destruction is modest.

Studies in the second group (design optimization), concentrate on how to improve the design of ICEs and related subsystems based on an exergy metric $[15,12,17]$. In [15], a Reformed Molecule HCCI (RM-HCCI) method is introduced. The results in [15], show that simpler fuel molecules cause less combustion irreversibility. Thus, reforming hydrocarbon fuels into small molecules under a specific condition leads to a higher SLT efficiency.

The third group in Figure 1 centers on the usage of exergy and SLT for control of ICEs. While exergy-based control has been studied before for different applications $[20,21,22]$ like Heating, Ventilation and Air conditioning (HVAC) with promising results by the authors of this paper [20,21], there are few studies focused on exergy-based control of ICEs. In [23], we designed a control algorithm to find optimum combustion phasing based on exergy for steady state operation of engines. This paper presents how to use exergy insight in control of ICEs for both steady-state and transient operations. Specifically, experimental SLT maps and predicted exergy loss/destruction have been generated based on physical models.

In different types of ICEs, combustion phasing is a commonly-used control variable since output power, engine-out emissions, combustion cyclic variations, and exhaust gas temperature are dependent on the combustion phasing [24, 25, 26]. Different control actuators have been used to adjust combustion phasing. For example, in conventional Compression Ignition (CI) engines, the fuel injection timing and number of in-cylinder injections are used for combustion phasing control while in SI engines, timing of spark ignition is used to control combustion phasing. In HCCI, since there is no direct means to initiate the combustion, combustion phasing is controlled by adjusting the charge properties including temperature, pressure and fuel-air concentrations [27, 28]. For HCCI combustion phasing control, different control actuators including dual fuel ratio adjustment [29, 30], intake air temperature adjustment [31] and Variable Valve Actuation (VVA) [32] have been used. In this study, an exergy-based optimal control method is introduced to adjust combustion phasing in ICEs.

Based on the application, the desired output of an ICE can be either power or Combined Power and Exhaust Exergy (CPEX). By minimizing exergy losses or maximizing SLT efficiency, the desired output exergy is increased. Exhaust exergy can be used in both stationary and mobile applications of energy systems. For example, turbochargers use exhaust exergy to boost the intake air pressure that leads 
to improve the automotive engine efficiency. Similarly, exhaust exergy is recovered in Combined Heat and Power (CHP) systems. In [18] exergy recovery for an CI engine is studied and authors experimentally showed that by recovering exhaust exergy, the Brake Specific Fuel Consumption (BSFC) decreases by 10\%. In [17] exhaust exergy recovery is studied for an ICE by using a Thermo-Electric Generator (TEG). Results in [17] show $5.2 \%$ increase in the effective thermal efficiency of the ICE.

Low Temperature Combustion (LTC) mode, compared to conventional SI or CI modes, leads to higher exergy efficiency [6]. In this paper, we focus on HCCI which is a well-recognized LTC mode for ICEs. Specifically, we use SLT efficiency as an accurate metric for engine control. An exergy model for a single cylinder HCCI engine is constructed. A crank angle resolved exergy analysis for a single-zone model is first conducted. Then, the SLT efficiency contour maps are generated based on 175 experimental data points for steady-state operation. A physical model is designed to predict instantaneous in-cylinder pressure, Start of Combustion (SOC), and CA50, i.e. the crank angle where $50 \%$ of the fuel mass is burnt. The predicted pressure trace is used to calculate exergy loss/destruction of different transient operating points. An optimization algorithm is formulated based on exergy to determine the optimum combustion phasing at every given engine load for transient and steady-state modes. Then, an algorithm for Exergy-based Control of ICE (XCICE) is developed. The new exergy-based control approach is illustrated by tracking the optimum CA50. CA50 is used in this study since it is a robust feedback indicator of HCCI combustion phasing due to the steep heat release in the main stage of HCCI combustion [33].

\section{Engine Experimental Data}

The experimental data from [24] for a single cylinder Ricardo HCCI engine at 175 different operating conditions are used. The specifications of the HCCI engine are listed in Table 1. This HCCI engine is a blended fuel engine using two Primary Reference Fuels (PRFs): n-Heptane with octane number (ON) of 0 (PRF0) and iso-Octane with ON of 100 (PRF100). The fuels are injected and pre-mixed with air in the intake manifold. More details about the operation of this engine and the experimental setup used for collecting the engine data are found in [24]. Figure 2 shows the engine operating range. As seen in Figure 2, the data represents a wide range of operation from naturally aspirated to boosted conditions with ultra lean or lean air-fuel mixtures. As Figure 2 shows, $P_{\text {man }}$ ranges from $90 \mathrm{kPa}$ (naturally aspirated) to $140 \mathrm{kPa}$ for intake charge boosting conditions. $T_{\text {man }}$ ranges from 340 $\mathrm{K}$ to $430 \mathrm{~K}$. These ranges represent the misfire and knock limits for the operating conditions tested at speeds of $800 \mathrm{rpm}$ to $1400 \mathrm{rpm}$ for the Ricardo engine in this work. More details can be found in [27]. 
Figure 3 shows the exhaust gas temperature $\left(T_{\text {exh }}\right)$ contour map for different engine loads (Indicated Mean Effective Pressure, IMEP) for the 175 points in this study. For these measurements the exhaust gas temperature sensor was located at the exhaust port. The data points in this contour map are the same as those in the SLT contour maps which will be shown later in the paper. In Figure 3, misfire and knock limits are shown for the studied engine operating range. Too delayed combustion phasing (i.e., CA50) at low loads causes misfire while knocking occurs at higher loads with too early CA50s. The top right region in Figure 3 shows the region that higher engine loads can be obtained once dilution is used, e.g., by using Exhaust Gas Recirculation (EGR). No EGR is used in this study. As seen in Figure 3, delayed combustion phasing leads to higher exhaust gas temperature.

\section{Engine Exergy Model}

For modeling and control of the studied ICE, the following assumptions have been made:

- In-cylinder gas mixture is an ideal gas mixture;

- It is a homogeneous air-fuel mixture;

- There is no intake charge cooling by fuel injections;

- There is no external gas recirculation;

- The expansion and compression are polytropic;

- Single-zone assumption is used to model the HCCI combustion process.

\subsection{Dead-State Condition}

The potential of a system to deliver work is defined with respect to a reference point that is called the dead-state condition. The restricted dead-state is used here and denoted by asterisk subscript ('*'). The restricted dead-state is defined as the condition when a system is at the same temperature and pressure with its reference environment (i.e., $T_{0}=298.15 \mathrm{~K}$ and $P_{0}=101.325 \mathrm{kPa}$ ) [3]; However, in the restricted dead-state, the chemical composition (e.g., molar mass of substances) may differ from the environment. Actual dead-state (or true dead-state) condition is the condition in which the system or mixture is in thermo-mechanical equilibrium and has chemical composition similar to that of the reference point (i.e., $75.67 \% \mathrm{~N}_{2}$, $20.35 \% \mathrm{O}_{2}, 3.03 \% \mathrm{H}_{2} \mathrm{O}, 0.03 \% \mathrm{CO}_{2}$, and $0.92 \%$ for other substances) [3]. To calculate the exergy flow of the processes during the engine operation, $P_{0}, T_{0}$ and dead-state air chemical molecular composition are used. 


\subsection{Exergy Balance}

The following equation governs the exergy balance for an ICE cylinder:

$$
\begin{gathered}
X_{F u e l}+X_{\text {Phys }, \text { in }}= \\
X_{\text {Work }}+X_{E x h}+\underbrace{\left(X_{d, \text { Comb }}+X_{H T}+X_{d, F r i c}\right)}_{X_{d}}+\underbrace{X_{U H C}+X_{\text {Blow-by }}+X_{d, M i x}}_{X_{\text {Others }}}
\end{gathered}
$$

where $X_{F u e l}$ is fuel exergy at Intake Valve Closing (IVC) moment. Physical exergy of the mixture at IVC is denoted with $X_{P h y s, i n}$ and is calculated by using Eq. (2a) by knowing temperature and pressure at IVC moment. $X_{W o r k}$ is the exergy transferred by work and the exhaust physical exergy is shown by $X_{E x h} . X_{d, C o m b}, X_{H T}$ and $X_{d, F r i c}$ are exergy destruction due to combustion, exergy loss due to heat transfer, and exergy destruction due to friction, respectively. Exergy loss corresponding to UHC is shown with $X_{U H C}$. To calculate $X_{U H C}$, the measured UHC data from emission analyzer is used in this paper [24]. $X_{\text {Blow-by }}$ denotes exergy losses due to blow-by gases. $X_{d, M i x}$ is the exergy destruction due to mixing. When two or more streams with different thermodynamic properties and chemical compositions mix, irreversible entropy is produced and exergy is destructed. The summation of other irrevrsibilities, $X_{d, M i x}$ and exergy losses including $X_{U H C}$, and $X_{B l o w-b y}$ is denoted by $X_{O t h e r s}$ term.

Flow of exergy in an engine is divided into two parts: physical and chemical. Physical exergy is related to the mixture's pressure and temperature. The difference in chemical composition of species with the respect to the reference environment compositions results in chemical exergy. Physical and chemical exergies of a system are determined by the following equations $[6]$ :

$$
\begin{aligned}
x_{\text {Phys }} & =\left(u-u_{*}\right)+P_{0}\left(v-v_{*}\right)-T_{0}\left(s-s_{*}\right) \\
x_{C h e m} & =\mu_{*}-\mu_{0} \\
\mu_{*} & =h_{*}-T_{0} s_{*} \\
\mu_{0} & =h_{0}-T_{0} s_{0}
\end{aligned}
$$

where $x_{\text {Phys }}$ and $x_{\text {Chem }}$ denote specific physical and specific chemical exergies of a system, respectively. Specific internal energy, the specific volume and specific entropy are denoted by $u, v$ and $s$, respectively. $\mu$ is the specific chemical potential in Eq. (2) and specific enthalpy of the in-cylinder mixture is shown by $h$.

For multi-component mixtures such as in-cylinder air-fuel mixture, the chemical potential of each species is calculated by using Eq. (2c) and Eq. (2d) [6] and then, the total mixture chemical potential is calculated using Eq. (3) [34]. 


$$
G_{m i x}=\mu_{m i x}=\sum_{i} \bar{\mu}_{i} n_{i}
$$

where $G_{m i x}$, and $\mu_{m i x}$ are the mixture Gibbs free energy and chemical potential of the mixture. $\bar{\mu}_{i}$ and $n_{i}$ denote chemical potential per mole and number of moles for species ' $i$ '.

Total specific exergy of a system $\left(x_{\text {total }}\right)$ is defined as the summation of specific physical and chemical exergies [3]:

$$
x_{\text {total }}=x_{\text {Phys }}+x_{\text {Chem }}
$$

The thermodynamic properties (in Eq. (2), Eq. (2c) and Eq. (2d)) for mixture species are dependent on in-cylinder gas temperature. Ideal gas law is used to calculate in-cylinder gas temperature. In order to calculate the thermodynamic properties in various conditions, NASA Polynomials [35] are used. NASA Polynomials include seven coefficients for species with temperatures less than $1000 \mathrm{~K}$ and seven constant coefficients for gases with the temperatures between $1000 \mathrm{~K}$ and $6000 \mathrm{~K}$ [35].NASA polynomial coefficients for a very large number of substances at different temperatures are found in [36].

$$
\begin{aligned}
\frac{c_{p}}{R_{u}} & =a_{1}+a_{2} T+a_{3} T^{2}+a_{4} T^{3}+a_{5} T^{4} \\
\frac{H}{R_{u} T} & =a_{1}+a_{2} \frac{T}{2}+a_{3} \frac{T^{2}}{3}+a_{4} \frac{T^{3}}{4}+a_{5} \frac{T^{4}}{5}+\frac{a_{6}}{T} \\
\frac{S}{R_{u}} & =a_{1} \ln T+a_{2} T+a_{3} \frac{T^{2}}{2}+a_{4} \frac{T^{3}}{3}+a_{5} \frac{T^{4}}{4}+a_{7}
\end{aligned}
$$

where $a_{1}, a_{2}, a_{3}, a_{4}, a_{5}, a_{6}, a_{7}$ are the polynomial coefficients [35]. $c_{p}$ and $R_{u}$ are the specific heat at constant pressure and the universal gas constant, respectively. $H$ and $S$ are enthalpy and entropy of in-cylinder species, respectively.

\subsubsection{Indicated Work Exergy}

Eq. (6) is used to calculate the rate of exergy transfer by work in the ICE. $X_{W o r k}$ in Eq. (1) is calculated by integrating Eq. (6) between IVC to EVO moments.

$$
\frac{d X_{W}}{d \theta}=\left(P-P_{0}\right) \frac{d V}{d \theta}
$$

where $P$ is the in-cylinder pressure and $\theta$ is the crank angle degree (CAD). $V$ is the instantaneous volume of cylinder. The crank-slider mechanism formulation from [37] 
is used to calculate $V$. Consequently, engine gross indicated work (i.e. closed cycle work) can be calculated by taking integral of Eq. (6) between IVC and EVO moments in time relative to crank angle [37].

\subsubsection{Exhaust Exergy}

Eq. (2a) is used to calculate exhaust exergy between EVO and EVC moments in time relative to crank angle. The exhaust exergy, $X_{E x h}$, is calculated by knowing the specific internal energy, volume and entropy of exhaust gas. For steady-state operation of ICE, experimentally measured pressure and temperature are used to find the thermodynamic properties of exhaust gases. For transient operation of ICE, pressure and temperature at EVO are estimated using the in-cylinder pressure model explained in Section 3.5.

\subsubsection{Combustion Irreversibility}

Any process in an ICE that involves temperature change, destructs exergy (i.e., work potential loss). Up to $25 \%$ of the fuel exergy is wasted during combustion process [6] which is the largest portion of exergy loss/destruction in a conventional ICE. The factors that affect combustion irreversibilities include: (1) fuel-air equivalence ratio, $\phi,(2)$ EGR rate, (3) fuel molecule complexity, and (4) inlet oxygen concentration $[15,38]$. For instance, by increasing $\phi$ values, the exergy destruction of combustion process decreases due to higher mixture temperature [6]. The following equation is used to calculate combustion irreversibility [3, 39]:

$$
d X_{d, C o m b}=-\frac{T_{0}}{T} \sum_{i}\left(\mu_{i} d m_{i}\right)
$$

where the differential of the exergy destruction due to combustion is denoted by $d X_{d, \text { Comb }}$. In Eq. (7), $\mu_{i}$ for fuel is considered to be equal to $x_{F u e l}$, and for other mixture species, $\mu_{i}$ is equal to the specific Gibbs free energy. As seen in Eq. (7), the combustion irreversibility depends on the in-cylinder mixture temperature, species type and changes in species mass $\left(d m_{i}\right)$ that is controlled by the chemical reaction rates and calculated based on Mass Fraction Burnt (MFB) at each crank angle.

\subsubsection{Exergy loss due to heat transfer}

In engine operation, exergy is lost due to heat transfer. Heat transfer term in this study accounts for the heat transfer from the in-cylinder mixture to the cylinder wall and the cylinder head. $X_{H T}$ in Eq. (1) is calculated by:

$$
\frac{d X_{H T}}{d \theta}=\left(1-\frac{T_{o}}{T}\right) \frac{d Q_{L}}{d \theta}
$$


where $\frac{d X_{H T}}{d \theta}$ denotes the rate of exergy loss due to heat transfer and $\left(1-\frac{T_{o}}{T}\right)$ is the Carnot cycle efficiency. To calculate the heat transfer rate (denoted by $\frac{d Q_{L}}{d \theta}$ ) in Eq. (8), modified Woschni correlation from [40] is used for the HCCI engine.

\subsubsection{Friction}

Chen \& Flynn correlation [37] is used to estimate Friction Mean Effective Pressure (FMEP) for the engine in this paper. Eq. (9) governs the exergy destruction due to friction [37].

$$
\begin{aligned}
& F M E P=c_{1}+c_{2} P_{\max }+c_{3} U_{p}+c_{4} U_{p}^{2} \\
& X_{d, \text { Fric }}=F M E P \times V_{d}
\end{aligned}
$$

Where $P_{\max }$ is the maximum cylinder pressure. $V_{d}$ and $U_{p}$ denote the engine displacement volume and the mean piston speed, respectively. The constants in (9a) $\left(c_{1}, c_{2}, c_{3}\right.$ and $\left.c_{4}\right)$ are determined based on engine experimental data. The experimental FMEP data from [41] was used to calculate the constant values in Eq. (9a) which are $c_{1}=0.20, c_{2}=0.004, c_{3}=0.007$, and $c_{4}=0.0008$. Friction plays a more significant role at high loads and high engine speeds, but it accounts for a small portion of exergy losses for the HCCI operating conditions in this study.

The contour map of $X_{d}$ (i.e., combined exergy destruction and exergy loss) with respect to the engine load (IMEP) and the combustion phasing (CA50) is shown in Fig. 4. As expected, more exergy destruction is observed during high engine load operations, since more fuel is burnt, compared to fuel burnt at lower loads. A proper selection of CA50 can reduce the amount of exergy $X_{d}$ at each engine load. As seen in Figure 4, too early combustion (e.g., $C A 50 \leq 4 C A D a T D C$ ) have higher $X_{d}$.

\subsubsection{Fuel Exergy}

Liquid hydrocarbon fuels for ICEs have a general structure of $C_{c} H_{h}$ in which subscripts 'c' and ' $h$ ' denote numbers of carbon and hydrogen atoms in the fuel molecule composition. Eq. (10) determines the approximate chemical exergy of hydrocarbon fuels based on the fuel Lower Heating Value (LHV) [42].

$$
x_{\text {Fuel }}=\left(1.04224+0.011925 \frac{h}{c}-\frac{0.042}{c}\right) \times L H V
$$

Where $x_{F u e l}$ denotes the specific chemical exergy of the fuel. The ratio of fuel exergy to LHV $\left(\frac{x_{F u e l}}{L H V}\right)$ which indicates the value of chemical exergy to chemical energy depends on the hydrocarbon type. This ratio for n-Heptane $\left(\mathrm{C}_{7} \mathrm{H}_{16}\right)$ and iso-Octane $\left(\mathrm{C}_{8} \mathrm{H}_{18}\right)$ are 1.06350 and 1.06382 , respectively. 


\subsection{Chemical Reaction}

A single-zone combustion model is used in this work which is intended for control applications. Single-zone model is computationally efficient but it is not highly accurate. However, multi-zone or CFD model can be used to increase accuracy but at the expense of time [43]. For control purpose, single-zone assumption has been widely used in the literature for control purposes [44].

The global chemical reaction for burning the blends of n-Heptane and iso-Octane is:

$$
\begin{gathered}
\left(1-\frac{O N}{100}\right) C_{7} H_{16}+\left(\frac{O N}{100}\right) C_{8} H_{18}+\left(11+\frac{3}{2} \frac{O N}{100}\right)\left(O_{2}+3.76 N_{2}\right) \Rightarrow \\
\left(\frac{O N}{100}+7\right) C_{2}+\left(\frac{O N}{100}+8\right) H_{2} O+3.76\left(\frac{3}{2} \frac{O N}{100}+11\right) N_{2}
\end{gathered}
$$

Stoichiometric air to fuel ratio (AFR) is denoted by $A F R_{\text {Stoich. }}$ and is determined by Eq. (12):

$$
A F R_{\text {Stoich. }}=\frac{\left(11+\frac{3}{2} \frac{O N}{100}\right) \times 4.76 \times M W_{a}}{\left(1-\frac{O N}{100}\right) \times M W_{n-H e p}+\left(\frac{O N}{100}\right) \times M W_{\text {iso-Oct }}}
$$

where $M W_{a}, M W_{n-H e p}$ and $M W_{i s o-O c t}$ are the molecular weights of air, n-Heptane and iso-Octane, respectively.

In HCCI, the combustion temperature is low, air-fuel mixture is homogeneous, and soot formation is ultra low. Thus, radiation is negligible in the HCCI engine in this study. In addition, in the HCCI engine, port fuel injection at low pressure (3 bar) is utilized and intake air at very high temperature is used (Fig.2); therefore, fuel atomization/vaporization effect on HCCI combustion is negligible for HCCI analysis. Depending on the ICE type, the effects from radiation, fuel atomization, fuel phase change/ charge cooling should be all taken into account and associated exergy destruction should be calculated.

\subsection{Second Law of Thermodynamics Efficiency}

The SLT efficiency is the ratio of the desired output exergy to the consumed exergy. For each application, the desired output is defined. If the resulting shaft work from in-cylinder mixture combustion is the desired output, the SLT efficiency is defined as [3]:

$$
\eta_{I I, W}=\frac{X_{W}}{X_{\text {Fuel }}+X_{\text {Phys }, \text { in }}}
$$


where $\eta_{I I, W}$ is the SLT efficiency when work is the desired output. Physical exergy of in-cylinder mixture at IVC, $X_{P h y s, i n}$, is very small compared to $X_{F u e l}$; Therefore, $X_{P h y s, i n}$ is neglected in some studies [3]. Thus, value of $\eta_{I I, W}$ is close to gross indicated thermal efficiency of the engine cycle $\left(\eta_{I}\right)$.

In other applications, Combined Power and Exhaust Exergy (CPEX) is the desired output. For instance, in boosted engines, the exhaust exergy is used in turbochargers in order to increase the intake manifold pressure. In addition, Thermoelectric Generator (TEG) uses the exhaust exergy to generate electricity; however, one should never sacrifice in-cylinder exergy work for increasing the exhaust exergy, when work exergy is the desired output since efficiency of exhaust recovery systems are low.

Eq. (14) determines the SLT efficiency of CPEX systems [3]:

$$
\eta_{I I, C P E X}=\frac{X_{W}+X_{E x h}}{X_{F u e l}+X_{P h y s, i n}}
$$

where $X_{E x h}$ is the average of the physical exergy of exhaust gases.

\subsection{In-cylinder Pressure Model}

There are many factors that affect in-cylinder pressure trace in an ICE. These factors include engine geometrical parameters, heat-release rate, intake manifold pressure and temperature $\left(P_{\text {man }}\right.$ and $\left.T_{m a n}\right)$, EGR, $\phi$, etc. An experimentally validated physics-based model is used to predict Start of Combustion (SOC) and End of Combustion (EOC) [29]. By knowing $P_{S O C}$ and $P_{E O C}$, we are able to predict the closed-cycle in-cylinder pressure trace. The closed-cycle pressure can be divided into three parts: (1) IVC to SOC, (2) SOC to EOC, and (3) EOC to EVO. A polytropic compression process is assumed to estimate the pressure trace between IVC to SOC [37]. To estimate pressure during combustion (SOC to EOC) heat-release which is determined based on fuel mass fraction burned $(M F B)$ is used. To this end, the modified Wiebe function is used to calculate $M F B$ [27]:

$$
M F B(\theta)=1-\exp \left(-a\left[\frac{\theta-S O C}{\theta_{d}}\right]^{b}\right)
$$

where $a$ and $b$ are the parameters of the Wiebe function, and $\theta_{d}$ denotes the combustion duration as a function of EGR rate and $\phi$. Combustion duration is calculated by using the following equation [27]:

$$
\theta_{d}=c(1+E G R)^{d} \phi^{e}
$$


where $c, d$ and $e$ are constant values. CA50 is the crank-angle by which $50 \%$ of the fuel mass is burnt (i.e., $M F B=0.5$ ).

To estimate the pressure between EOC and EVO a polytropic assumption is used [37]. The predicted pressure trace will be used to calculate exergy losses/destructions during an engine cycle. Fig. 5 demonstrates pressure trace validation for four different ICE conditions. The results show a good agreement between predicted and measured pressure trace.

The predicted in-cylinder pressure model can be used to predict exergy destruction/losses for different engine conditions. If in-cylinder pressure sensors are available in the engine, the predicted pressure trace values can be replaced by real in-cylinder pressure measurements. In this study, measured in-cylinder pressure $\left(P_{C y l}\right)$ data is used for exergy analysis of 175 steady-state experimental data. The in-cylinder pressure model is used for predicting $P_{C y l}$ for the conditions that measured data is not available to us, particularly during engine transients.

\section{Exergy Analysis}

\subsection{Crank-Angle Resolved Exergy Analysis}

Measured in-cylinder pressure data [24] with 0.1 CAD resolution is used to analyze exergy change from IVC to EVO. The pressure trace data is used to calculate the engine exergy loss/destruction and exergy transfer by work for the engine conditions shown in Figures 2 and 3. Ideal gas assumption is used to calculate the in-cylinder mixture temperature. Fig. 6 shows a crank-angle resolved exergy analysis of the cylinder for an arbitrary operating point using engine cylinder as the control volume. Negative values in Fig. 6 show that the exergy of cylinder is lost or destructed. Fig. 6 (a) shows the rate of indicated work using Eq. (6). Fig. 6 (b) demonstrates combustion irreversibility rate using Eq. (7) and the rate of exergy loss due to heat-transfer using Eq. (8). As seen in Fig. 6 (b), heat-loss rate increases during compression which results in mixture temperature rise. After SOC moment, combustion irreversibility rate and heat-loss rate increase considerably. At the end of combustion phase, EOC moment, the rate of combustion irreversibility becomes zero and the rate of exergy loss due to heat-transfer slowly decreases since mixture temperature decreases gradually. Fig. 6 (c) shows the cumulation of Fig. 6 (a) and (b) which shows the exergy destruction/loss and exergy transfer during the closed cycle (i.e., IVC to EVO). Air and fuel mass flow rates are obtained from the experimental measurements in [24]. Eq. (10) is used to calculate fuel exergy $\left(X_{F u e l}\right)$ which is converted to $X_{W}, X_{E x h}$ and $X_{d}$ during the four strokes of the ICE.

Fig. 7 shows the breakdown of energy and exergy distribution for the same operating point shown in Fig. 6. The percentages of indicated work, heat loss, and 
exhaust gas energy and exergy are shown in Fig. 7. In addition to these terms, for the exergy distribution, friction, combustion irreversibility, and other exergy losses including blow-by gases, UHC, and mixing are shown. Due to $6.4 \%$ difference between fuel LHV and specific exergy (see Eq. (10)), the values of work in exergy and energy breakdown are not equal $[3,5]$. As seen in Fig. 7 , there is a difference between heat loss values in energy and exergy breakdown. The reason for this difference is that only $70 \%$ of the transferred heat (i.e., energy) can do work (i.e., exergy) and the rest of energy which is $30 \%$ of the transferred energy by heat, does not have potential to do work. In the same way, exhaust gases account for $43 \%$ of the fuel energy but only $16 \%$ of fuel exergy.

As seen in Fig. 7, the exergy destruction due to combustion is the main source of exergy loss accounting for more than $40 \%$ of the total exergy loss. In this operating point, $5 \%$ of fuel exergy is destroyed due to friction. Exergy losses due to blow-by, and, UHC and exergy destruction due to mixing of air-fuel charge and residual gases are shown in a category shown by 'Other irreversibilities' in Fig. 7 that account for $9 \%$ of fuel exergy loss. $\eta_{I_{W}}$ and $\eta_{I_{C P E X}}$ are $38 \%$ and $55 \%$, respectively for the operating point shown in Fig. 7.

\subsection{SLT Contour Maps}

Based on Equations (13) and (14) and using the ICE experimental data shown in Figs. 2 and 3, two different SLT efficiency contour maps are generated. These maps are used to find the optimum combustion phasing for steady-state operation of the engine.

Fig. 8 shows the SLT contour map $\left(\eta_{I I, W}\right)$ as a function of combustion phasing (CA50) and engine load (IMEP). Fig. 9 shows the SLT efficiency $\left(\eta_{I I, C P E X}\right)$ map for CPEX based on Eq. (14).

\section{Exergy-based Control}

In this section, a control oriented engine model is used to track the optimal combustion phasing trajectories which are determined by maximizing SLT efficiency.

\subsection{Exergy-based Optimal Combustion Phasing (XOCP)}

In this section, an optimization algorithm is introduced to determine optimum combustion phasing trajectories for given engine load sweeps. This algorithm is based on the SLT maps and will be used for steady-state operation of the ICE. $C A 50_{O P T}$ trajectories are based on the contour maps of $\eta_{I I, W}$ and $\eta_{I I, C P E X}$ (Figs. 8 and 9). Fig. 10 demonstrates the details of the proposed Exergy-based Optimal Combustion 
Phasing (XOCP) algorithm. Desired IMEP is an input to the XOCP algorithm. At every given IMEP, the corresponding CA50 is determined such that $\eta_{I I, W}$ or $\eta_{I I, C P E X}$ is maximized. When the required engine load is changed, XOCP finds the $C A 50_{O P T}$ according to the maps in Figs. 8 and 9.

The $C A 50_{O P T}$ at different engine loads based on the proposed XOCP algorithm are shown in Figs. 8 and 9. $C A 50_{O P T}$ trajectory, shown in Fig. 8, is the optimum CA50 that maximizes the SLT efficiency $\left(\eta_{I I, W}\right)$ at every given engine load. As seen in Fig. 8, in low load engine operation, the mid-range CA50 values result in the maximum $\eta_{I I, W}$. At higher engine loads, a delayed combustion phasing results in higher $\eta_{I I, W}$. Similar to Fig. 8, at every given engine load, the corresponding CA50 of the maximum value of $\eta_{I I, C P E X}$ is selected. Comparing $C A 50_{O P T}$ trajectories in Figs. 8 and 9 shows that the maximum $\eta_{I I, C P E X}$ occurs at higher CA50 values compared to $\eta_{I I, W}$. This can be explained by the fact that higher CA50 values (i.e., delayed combustion) lead to higher $T_{e x h}$ which increases $X_{E x h}$. Considering $X_{E x h}$ as the useful output exergy in CPEX systems leads to greater values of efficiency for $\eta_{I I, C P E X}$ compared to $\eta_{I I, W}$.

As seen in Figs. 8 and 9, the obtained trajectories are affected by the existence of efficiency islands in Figs. 8 and 9. These islands depends on the experimental data points used. Thus, it is important that enough engine data points are collected to generate the $\eta_{I I}$ efficiency maps. The focus of this study is more on proposing a methodology for optimum engine operation rather than absolute $\eta_{I I}$ values.

\subsection{Control Oriented Engine Model}

In this paper, we introduce a control method for ICEs based on exergy. This control method consists of steady-state and transient operation modes. In the steadystate operation of the engine, SLT maps (Figs. 8 and 9) are used to find $C A 50_{O P T}$. For the transient operation of the ICE, in-cylinder pressure is predicted using the model introduced in Sec. 3.5. Then the model is used along with exergy Equations (1) to (16). Next, the resulting model is combined with the model in [29] for estimating residual gas and capturing thermal coupling dynamics that are caused by residual gases from one cycle to the next engine cycle. The final model is able to predict cycle-to-cycle combustion phasing, IMEP and exergy destruction/loss in transient operation. The final nonlinear model is represented by the following state equations:

$$
\begin{aligned}
& \mathcal{X}_{k+1}=f\left(\mathcal{X}_{k}, \mathcal{U}_{k}, \mathcal{V}_{k}\right) \\
& \mathcal{Y}=\mathcal{C} \mathcal{X}_{k}
\end{aligned}
$$


where $\mathcal{X}$ is the vector of states, $\mathcal{U}$ is the vector of inputs and $\mathcal{V}$ is the vector of disturbances. The control inputs and states of the ICE model are as following:

$$
\mathcal{X}=\left[C A 50, T_{S O C}, P_{S O C}, T_{r g}, m_{E V C}\right]^{T}
$$

where $T_{S O C}$ and $P_{S O C}$ are the temperature and pressure of in-cylinder mixture at SOC, respectively. $T_{r g}$ denotes residual gas temperature and $m_{E V C}$ shows mass of residual gases at EVC moment.

Selection of the control inputs was based on the sensitivity analysis performed in $[28,45]$. The control inputs vector consists of $O N$ and $\phi$ as shown in Eq. (19):

$$
u=[O N, \phi]^{T}
$$

The developed control model has two primary control inputs including fuel-air equivalence ratio and fuel ON. This model has two outputs of CA50 and IMEP, and five states of CA50, $T_{S O C}, P_{S O C}, T_{r g}$, and $m_{E V C}$. The assumptions for developing this model are listed on Section 3. The governing physics are from [24, 27, 29, 37] that have been cited in Section 3 .

\subsection{Exergy-based Control of Internal Combustion Engines (XCICE)}

Structure of the proposed XCICE controller is shown in Fig. 11. The XCICE controls combustion phasing (CA50) and engine load (IMEP). Depending on the required IMEP, a map-based feedforward integral controller adjusts the engine load by manipulating the amount of injected fuel (i.e., fuel equivalence ratio, $\phi$ ). Details of the IMEP controller are found in [46]. The reference optimum CA50, shown as $\tilde{y}_{2, \text { ref }}$ in Fig. 11 is determined by $I M E P-C A 50-\eta_{I I}$ map (Figs. 8 and 9) for steady-state operation. For transient operation, $\tilde{y}_{2, \text { ref }}$ is found using exergy model along with an optimal controller to choose CA50 such that exergy loss/destruction $\left(X_{d}\right)$ is minimized.

Eq. (20) defines the control problem to find $C A 50_{O P T}$ for transient engine operation. We use $X_{d}$ in Eq. (1) as the objective function. The following optimization problem is solved at each engine cycle $k$. 


$$
\begin{aligned}
& \min _{C A 50}\left\{X_{d}\right\} \\
& \text { subject to: } \\
& \mathcal{X}_{k+1}=f\left(\mathcal{X}_{k}, \mathcal{U}_{k}, \mathcal{V}_{k}\right) \\
& \mathcal{Y}=\mathcal{C} \mathcal{X}_{k} \\
& 0 \leq O N_{k} \leq 100 \\
& \underline{C A 50} \leq C A 50_{k} \leq \overline{C A 50} \\
& \underline{\delta}^{\circ} \leq C A 50_{k+1}-C A 50_{k} \leq \bar{\delta}^{\circ}
\end{aligned}
$$

where Eq. (20d) shows the constraint on $O N$ as the control input. Eq. (20e) is the output constraint on CA50 based on knock and misfire data [24] in which $\underline{C A 50}$ and $\overline{C A 50}$ are the lower and upper limits of combustion phasing. Due to the actuator limitations, Eq. (20f) is defined to impose constraints on the rate of changes in combustion phasing at lower and upper limits denoted with $\underline{\delta}^{\circ}$ and $\bar{\delta}^{\circ}$.

Once the desired CA50 is determined, the ON (i.e., blending ratio of two PRF fuels) is adjusted using an integral state feedback controller described in [30]. This feedback controller tracks the desired CA50 values. The integrator in the controller helps to track the desired combustion phasing trajectory with no steady-state error. A Luenburger state observer is used in the control structure since most of the control states cannot be measured in practice. This controller is tested on a detailed experimentally validated ICE plant model [44]. The tracking results of the proposed exergy-based controller for transient engine operation are shown in Fig. 12. An IMEP trajectory $(4.43 \rightarrow 4.56 \rightarrow 4.62$ bar $)$ in Fig. 12 (c) is used as the reference load trajectory to test the proposed transient controller. The IMEP trajectory is similar to the loads shown in Fig. 8. The controller tracks the $C A 50_{O P T}$ using exergy model in optimization framework shown in Eq. (20). Fig. 12 (a) shows the CA50 tracking performance with a settling time of one engine cycles. Fig. 12 (b) shows the actuated ON as the control input for tracking the desired CA50. Fig. 12 (c) shows the required IMEP, and Fig. 12 (d) shows the actuated input, $\phi$ to obtain the required IMEP. Fig. 12 (e) demonstrates $X_{d}$ for optimum CA50 trajectory and unoptimized case (i.e., $C A 50=8 C A D a T D C$ ). As shown in Fig. 12 (e), the optimization algorithm introduced in Eq.(20) keeps $X_{d}$ minimum for all transient cycles compared to the unoptimized case.

Note, boundary conditions imposed on the exergy model can affect the performance of the controller. First, the exergy model is affected by thermal boundary 
conditions, e.g. cylinder wall temperatures. As a result, the effects of cylinder wall temperature are accounted for in the heat transfer model in the exergy model. Second, other boundary conditions also can affect the exergy analysis. As long as the boundary conditions are accurately estimated/measured and provided to the model, the model-based exergy-wise controller has performed as anticipated during transient engine operations. In addition, adaptive control schemes [47] can be developed to overcome exergy modeling uncertainty due to uncertain boundary conditions; thus, sensitivity of the proposed exergy-wise controller can be minimized against uncertain boundary conditions.

\section{Optimization Results}

Depending on the application of an ICE, the desired output and the SLT efficiency are defined. For ICE applications in which output work is of primary interest, the $C A 50_{O P T}$ trajectory of $\eta_{I I, W}$ is used to increase the SLT efficiency and improve the fuel economy. If CPEX is desired, then $\eta_{I I, C P E X}$ map is used to determine optimum combustion phasing to maximize output exergy $\left(X_{W o r k}+X_{E x h}\right)$.

The $C A 50_{O P T}$ trajectories based on $\eta_{I I, W}$ and $\eta_{I I, C P E X}$ maps are used to show the effects of the proposed XCICE in fuel saving and output exergy saving in Fig. 13. Experimentally calculated $\eta_{I I, W}$ map (shown in Fig. 8) is used to compare fuel consumption. The baseline for comparison is a conventional practice where CA50 is maintained constant (i.e., $8 C A D a T D C$ ). The fuel consumption for the optimization modes of $\eta_{I I, W}$ and $\eta_{I I, C P E X}$ is compared with that of the baseline.

As shown in Fig. 13 (a), CA50 OPT shown in $\eta_{I I, W}$ map leads to the best fuel saving at every given IMEP. Fig. 13 (b) demonstrates the increase in total output exergy (CPEX) when CA50 is selected based on $\eta_{I I, C P E X}$ map (i.e., Fig. 9).

Table 2 summarizes the fuel and exergy savings using the optimum combustion phasing values derived from the trajectories illustrated on $\eta_{I I, W}$ and $\eta_{I I, C P E X}$ maps. Compared to the unoptimized case, the average achieved fuel saving and exergy saving based on the $\eta_{I I, W}$ optimization mode are $6.7 \%$ and $7.2 \%$, respectively. However, if maximizing CPEX is of interest, by using the $\eta_{I I, C P E X}$ optimization mode, the average output exergy saving $\left(X_{W o r k}+X_{E x h}\right)$ is $8.3 \%$ while $5.7 \%$ fuel saving is achieved.

Note, selection of $C A 50=8 C A D a T D C$ is a common practice based on the FLT analysis. Comparisons of the SLT performance results with those from FLT are provided in Table 2 and Fig. 12 in which $C A 50=8 C A D a T D C$ (i.e., Unoptimized) is the outcome of the FLT analysis [27]. In addition, as mentioned in Section 3.4, value of $\eta_{I I, W}$ is close to thermal efficiency of the engine cycle, $\eta_{I}$. Thus, exergy 
and fuel savings can be compared to the commonly used thermal efficiency by using $\eta_{I I, W}$ values.

\section{Summary and Conclusion}

In this work, exergy is introduced as an effective metric to control the performance of ICEs. We present a novel approach for Exergy-based Control of ICEs (XCICE) for steady-state and transient engine operations. First, an exergy model for a singlecylinder HCCI engine was developed. Then, an exergy analysis carried out using the exergy model along with the experimental engine data. The main sources of exergy loss/destruction including combustion irreversibility, heat-loss, and friction are identified based on the exergy analysis results. Depending on the ICE applications, two different SLT efficiency maps were generated. The first SLT map was to maximize the output work, while the second SLT map aimed for maximizing Combined Power and Exhaust Exergy (CPEX). The optimal combustion phasing (i.e., $C A 50_{O P T}$ ) at every given IMEP was determined (i) using SLT maps for steady-state engine operation and (ii) using exergy model within Model Predictive Control (MPC) framework for engine transient ICE. A control method to track $C A 50_{O P T}$ and IMEP was developed for both transient and steady-state engine operations.

This paper focuses on combustion control while control of the intake charge process (e.g., turbo-charger, intake charge cooling, etc.) as well as exhaust stroke (e.g. for rebreathing, residual gas control, etc.) are not included in this study. The studied engine has "zero" valve overlap running in HCCI mode, and valve timings are fixed. Thus the sole focus of the paper is on the closed part of the engine cycle for combustion controls.

Here is the list of major findings from this work for the studied engine:

- Exergy destruction due to combustion $\left(X_{d, C o m b}\right)$ is the main source of exergy loss in the ICE. Combustion irreversibility accounts for more than $40 \%$ of total in-cylinder exergy destruction/losses for the 175 experimental data points in this study. Heat-transfer, $X_{H T}$, causes $12 \pm 3 \%$ of the fuel exergy loss. In addition, $9 \pm 4 \%$ of the fuel exergy is lost/destroyed due to mixing irreversibility, unburnt hydrocarbons, and blow-by gases. Finally, in-cylinder friction, $X_{d, F r i c}$, destroys $4 \pm 0.5 \%$ of the total exergy.

- The results of the proposed optimization method were compared to those from a conventional approach in which a constant $(C A 50=8 C A D a T D C)$ is used. The results show that on average, the proposed method can reduce the fuel consumption by $6.7 \%$ when the output work is of interest. For cases in which 
CPEX is desired, such as CHP systems, the proposed method can increase the desired output exergy by $8.3 \%$ on average.

- Transient control of the engine via exergy-based MPC framework can minimize $X_{d}$ while meeting required IMEP. The simulation results showed up to $5 \%$ reduction in $X_{d}$ by using the proposed transient control for the engine load sweep in this study.

- Results from this study illustrated that $\eta_{I I, W}$ map along with exergy breakdown of engine cycle can be used to determine the maximum available work (exergy). Exhaust exergy can be utilized in a turbocharger or a TEG system in order to increase the engine output work. Typical efficiency of TEG systems for ICEs is around 5-8\% [48]. Depending on the exhaust gas temperature and pressure, the FLT and SLT efficiencies of the overall energy recovery system could be as low as $8 \%$ and $24 \%$, respectively [49]. Thus, when indicated work is the desired output, one should never sacrifice work exergy for increasing the exhaust exergy.

XCICE requires to have an accurate engine exergy model and exergy loss/ destruction models across the engine components. The implementation of the XCICE for steady state operation is similar to the conventional map-based engine control but uses the SLT maps instead. For transient operations, the only difference is the change in the objective function (Eq. (20)) in the optimal control framework. Depending on the complexity of the exergy objective function, XCICE can be computationally expensive.

The key outcome from this study is to show how the knowledge from an exergy analysis can be used for ICE controls. The proposed XCICE method is generic and can be applied to a wide range of ICEs. We presented the results for a specific type of LTC engine known as HCCI with ON and $\phi$ as the control variables, yet the same XCICE method can be applied to other ICEs with different combustion modes and control inputs.

\section{Acknowledgements}

This work was supported in part by the US National Science Foundation (Grant \#1434273) and the Richard and Elizabeth Henes Professorship of Mechanical Engineering at Michigan Technological University. The authors gratefully acknowledge Professor Bob Koch from the University of Alberta for providing the experimental data [24] used in this work and Mr. Mohammadreza Nazemi for his technical comments during the course of this study. 


\section{References}

[1] R.D. Robinett III and D.G. Wilson. "Nonlinear Power Flow Control Design: Utilizing Exergy, Entropy, Static and Dynamic Stability, and Lyapunov Analysis". Chapter 2, Springer Science \& Business Media, 2011.

[2] K.D. Edwards, R.M. Wagner, T.E. Briggs, and T.J. Theiss. "Defining Engine Efficiency Limits". In $17^{\text {th }}$ DEER Conference, Detroit, MI, October, pages 3-6, 2011.

[3] C.D. Rakopoulos and E.G. Giakoumis. "Second-law analyses applied to internal combustion engines operation". Progress in Energy and Combustion Science, 32(1):2-47, 2006.

[4] M. Djermouni and A. Ouadha. "Thermodynamic analysis of an HCCI engine based system running on natural gas". Energy Conversion and Management, 88:723-731, 2014.

[5] J.A. Caton. "A Review of Investigations Using the Second Law of Thermodynamics to Study Internal-Combustion Engines". SAE Paper 2000-01-1081, 2000 .

[6] S. Saxena, N. Shah, I. Bedoya, and A. Phadke. "Understanding optimal engine operating strategies for gasoline-fueled HCCI engines using crank-angle resolved exergy analysis". Applied Energy, 114:155-163, 2014.

[7] S. Jafarmadar, P. Nemati, and R. Khodaie. "Multidimensional modeling of the effect of Exhaust Gas Recirculation (EGR) on exergy terms in an HCCI engine fueled with a mixture of natural gas and diesel". Energy Conversion and Management, 105:498-508, 2015.

[8] I. Sezer and A. Bilgin. "Exergy analysis of SI engines". International Journal of Exergy, 5(2):204-217, 2008.

[9] I. Sezer and A. Bilgin. "Effects of Charge Properties on Exergy Balance in Spark Ignition Engines". Fuel, 112:523-530, 2013.

[10] R. Ghahfarokhi Fatehi, S. Khalilarya, and R. Ebrahimi. "Energy and exergy analyses of homogeneous charge compressin ignition (HCCI) engine". Thermal Science, 17(1):107-117, 2013. 
[11] J.A. Caton. "On the destruction of availability (exergy) due to combustion processeswith specific application to internal-combustion engines". Energy, 25(11):1097-1117, 2000.

[12] T. Endo, S. Kawajiri, Y. Kojima, K. Takahashi, T. Baba, S. Ibaraki, T. Takahashi, and M. Shinohara. "Study on Maximizing Eexergy in Automotive Engines". SAE Paper 2007-01-0257, 2007.

[13] A.K. Amjad, R. Khoshbakhti Saray, S.M.S. Mahmoudi, and A. Rahimi. "Availability analysis of n-heptane and natural gas blends combustion in HCCI engines". Energy, 36(12):6900-6909, 2011.

[14] Daniel P Madison. "Thermal Characterization of a Gasoline Turbocharged Direct Imjection (GTDI) Engine Utilization Lean Operation and Exhaust Gas Recirculation (EGR)". PhD thesis, 2013.

[15] F. Yan and W. Su. "A Promising High Efficiency RM-HCCI Combustion Proposed by Detail Kinetics Analysis of Exergy Losses". SAE Paper 2015-01-1751, 2015.

[16] F. Yan and W. Su. "Numerical Study on Exergy Losses of n-Heptane Constant-Volume Combustion by Detailed Chemical Kinetics". Energy \& Fuels, 28(10):6635-6643, 2014.

[17] C. Zhang, G. Shu, H. Tian, H. Wei, G. Yu, and Y. Liang. "Theoretical Analysis of a Combined Thermoelectric Generator (TEG) and Dual-loop Organic Rankine Cycle (DORC) System Using for Engines' Exhaust Waste Heat Recovery". SAE Paper 2014-01-0670, 2014.

[18] M. Ghazikhani, M. Hatami, D. Domiri Ganji, M. Gorji-Bandpy, A. Behravan, and G. Shahi. "Exergy recovery from the exhaust cooling in a DI diesel engine for BSFC reduction purposes". Energy, 65:44-51, 2014.

[19] S. Song, H. Zhang, Z. Lou, F. Yang, K. Yang, H. Wang, C. Bei, Y. Chang, and B. Yao. "Performance analysis of exhaust waste heat recovery system for stationary CNG engine based on organic Rankine cycle". Applied Thermal Engineering, 76:301-309, 2015.

[20] M. Razmara, M. Maasoumy, M. Shahbakhti, and R.D. Robinett III. "Optimal exergy control of building HVAC system". Applied Energy, 156:555-565, 2015. 
[21] M. Razmara, M. Maasoumy, M. Shahbakhti, and R.D. Robinett III. "ExergyBased Model Predictive Control for Building HVAC Systems". In American Control Conference (ACC), pages 1677-1682, 2015.

[22] N. Jain and A. Alleyne. "Exergy-based optimal control of a vapor compression system". Energy Conversion and Management, 92:353-365, 2015.

[23] M. Razmara, M. Bidarvatan, M. Shahbakhti, and R. D. Robinett III. "Innovative Exergy-Based Combustion Phasing Control of IC Engines". SAE Paper 2016-01-0815, 2016.

[24] M. Shahbakhti and C.R. Koch. "Characterizing the cyclic variability of ignition timing in a homogeneous charge compression ignition engine fuelled with n-heptane/iso-octane blend fuels". International Journal of Engine Research, 9(5):361-397, 2008.

[25] M. R. Amini, M. Shahbakhti, and A. Ghaffari. "A Novel Singular Perturbation Technique for Model-based Control of Cold Start Hydrocarbon Emission". SAE International Journal of Engines, 7(2014-01-1547):1290-1301, 2014.

[26] M. Shahbakhti, M. R. Amini, J. Li, S. Asami, and J. K. Hedrick. "Early Model-Based Design and Verification of Automotive Control System Software Implementations". Journal of Dynamic Systems, Measurement, and Control, 137(2):021006, 2015.

[27] M. Shahbakhti. "Modeling and Experimental Study of an HCCI Engine for Combustion Timing Control". PhD thesis, Department of Mechanical Engineering, University of Alberta, 2009.

[28] M. Shahbakhti, R. Lupul, and C. R. Koch. "Sensitivity analysis and modeling of HCCI auto-ignition timing". In Advances in Automotive Control, volume 5, pages 303-310, 2007.

[29] M. Bidarvatan, M. Shahbakhti, S.A. Jazayeri, and C.R. Koch. "Cycle-to-cycle modeling and sliding mode control of blended fuel HCCI engine". Control Engineering Practice, 24:79-91, 2014.

[30] M. Bidarvatan, M. Shahbakhti, and S.A. Jazayeri. "Model-based Control of Combustion Phasing in an HCCI Engine". SAE International Journal of Engines, 5(3):1163-1176, 2012. 
[31] S. Saxena, J.-Y. Chen, and R. Dibble. "Maximizing Power Output in an Automotive Scale Multi-Cylinder Homogeneous Charge Compression Ignition (HCCI) Engine". SAE Paper 2011-01-0907, 2011.

[32] G.M. Shaver, J.C. Gerdes, and M.J. Roelle. "Physics-based modeling and control of residual-affected HCCI engines". ASME Journal of Dynamic Systems, Measurement, and Control, 131(2), 2009.

[33] J. Bengtsson, P. Strandh, R. Johansson, P. Tunestål, and B. Johansson. "Hybrid control of homogeneous charge compression ignition (HCCI) engine dynamics". International Journal of Control, 79(05):422-448, 2006.

[34] D. Kondepudi and I. Prigogine. "Modern Thermodynamics: From Heat Engines to Dissipative Structures". Chapter 5, John Wiley \& Sons, 2014.

[35] A. Burcat. "Thermochemical data for combustion calculations". In Combustion Chemistry, pages 455-473. Springer, 1984.

[36] A. Burcat. "Ideal Gas Thermodynamic Data in Polynomial form for Combustion and Air Pollution Use", Available: http://garfield.chem.elte.hu/Burcat/burcat.html, (Aug. 9 ${ }^{\text {th }}, 2016$ ).

[37] J.B. Heywood. "Internal Combustion Engine Fundamentals". McGraw-Hill New York, 1998.

[38] J. A. Caton. "Exergy destruction during the combustion process as functions of operating and design parameters for a spark-ignition engine". International Journal of Energy Research, 36(3):368-384, 2012.

[39] C.D. Rakopoulos and E.C. Andritsakis. "DI and IDI Diesel Engines Combustion Irreversibility Analysis". Proceedings of the 1993 ASME Winter Annual Meeting, 1993.

[40] J. Chang, O. Güralp, Z. Filipi, D.N. Assanis, T.W. Kuo, P. Najt, and R. Rask. "New Heat Transfer Correlation for an HCCI Engine Derived from Measurements of Instantaneous Surface Heat Flux". SAE Paper 2004-01-2996, 2004.

[41] R. A. W. Lupul. "Steady State and Transient Characterization of a HCCI Engine with Varying Octane Fuel". Master's thesis, Department of Mechanical Engineering, University of Alberta, 2008. 
[42] M.J. Moran. "Availability analysis: a guide to efficient energy use". New Jersey: Prentice-Hall Inc., Oxford, 1982.

[43] M. Nazemi and M. Shahbakhti. "Modeling and analysis of fuel injection parameters for combustion and performance of an RCCI engine". Applied Energy, 165:135-150, 2016.

[44] M. Shahbakhti and C.R. Koch. "Physics Based Control Oriented Model for HCCI Combustion Timing". ASME Journal of Dynamic Systems, Measurement, and Control, 132(2), 2010.

[45] "HCCI Engine Cyclic Variation Characterization Using Both Chaotic and Statistical Approach, author=Ghazimirsaied, A. and Shahbakhti, M. and Audet, A. and Koch, C.R., booktitle=Proceeding of Combustion Institue-Canadian Section, Spring Technical Meeting, year $=2008$.

[46] M. Bidarvatan and M. Shahbakhti. "Two-input two-output control of blended fuel HCCI engines". SAE Paper 2013-01-1663, 2013.

[47] M.R. Amini, M. Shahbakhti, S. Pan, and K. Hedrick. "Handling Model and Implementation Uncertainties via an Adaptive Discrete Sliding Mode Controller Design". In 2016 ASME Dynamic Systems Control Conference. American Society of Mechanical Engineers (ASME), 2016.

[48] Wikipedia: The Free Encyclopedia. "Thermoelectric Generator", available from: https : //en.wikipedia.org/wiki/thermoelectric_generator, retrieved, 10 october, 2015.

[49] C.W. Chan, J. Ling-Chin, and A.P. Roskilly. "A review of chemical heat pumps, thermodynamic cycles and thermal energy storage technologies for low grade heat utilisation". Applied Thermal Engineering, 50(1):1257-1273, 2013. 
Table 1: Specifications of the single cylinder Ricardo HCCI engine.

\begin{tabular}{lc}
\hline \hline Parameter & Value \\
\hline Bore & $80 \mathrm{~mm}$ \\
Stroke & $88.90 \mathrm{~mm}$ \\
Compression Ratio (CR) & $10: 1$ \\
Displacement volume $\left(V_{d}\right)$ & $447 \mathrm{cc}$ \\
Number of valves & 4 \\
Intake valve opening (IVO) & $-175^{\circ} \mathrm{aBDC}^{*}$ \\
Intake valve closing (IVC) & $+55^{\circ} \mathrm{aBDC}$ \\
Exhaust valve opening (EVO) & $-70^{\circ} \mathrm{aBDC}$ \\
Exhaust valve closing (EVC) & $-175^{\circ} \mathrm{aBDC}$ \\
\hline \hline
\end{tabular}

*After bottom dead center.

Table 2: Comparison of the fuel and exergy savings for different optimization modes.

\begin{tabular}{|c|c|c|c|}
\hline $\begin{array}{c}\text { Optimization } \\
\text { Mode }\end{array}$ & $\begin{array}{c}\text { Combustion } \\
\text { Phasing }\end{array}$ & $\begin{array}{c}\text { Avg. Energy } \\
\text { Saving (\%) }\end{array}$ & $\begin{array}{c}\text { Avg. Exergy } \\
\text { Saving (\%) }\end{array}$ \\
\hline$\eta_{I I, W}$ & Variable CA50 & 6.7 & 7.2 \\
\hline$\eta_{I I, C P E X}$ & Variable CA50 & 5.7 & 8.3 \\
\hline Unoptimized* $^{*}$ CA50 $=8^{\circ} a T D C$ & - & - \\
\hline
\end{tabular}




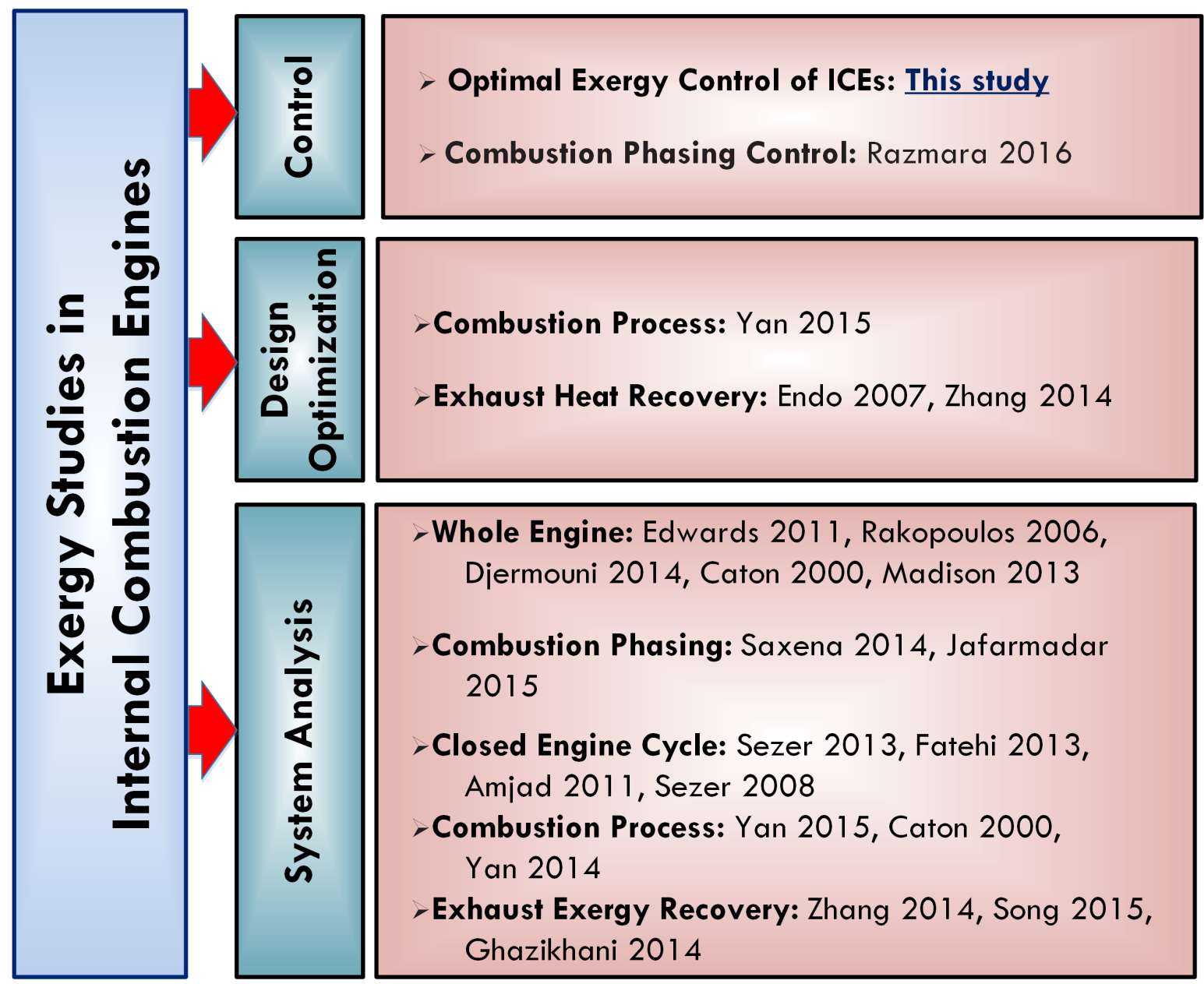

Figure 1: Research background of SLT and exergy studies in ICEs. 
(a)

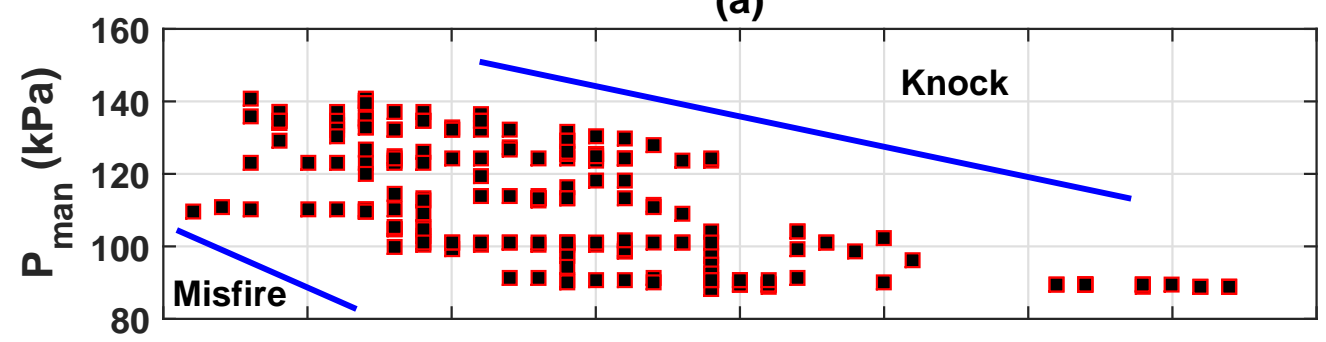

(b)

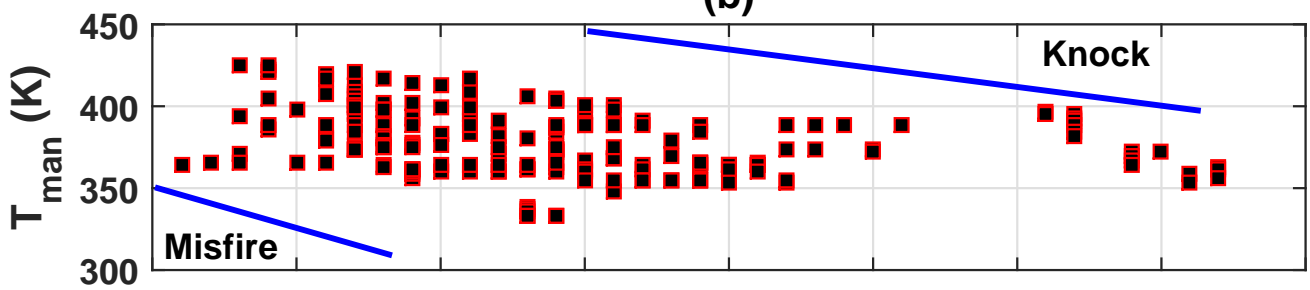

(c)

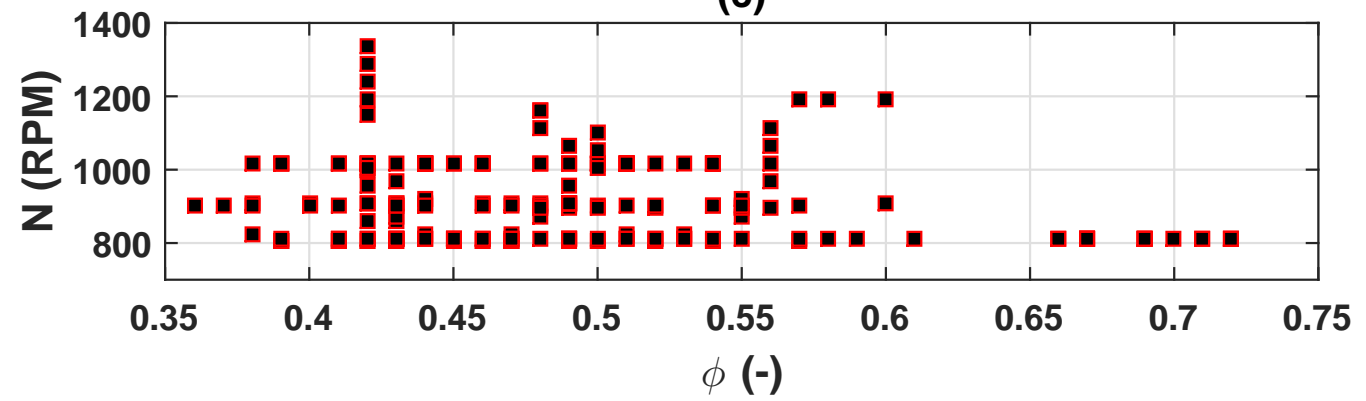

Figure 2: Engine operating range for 175 steady-state data-points without external Exhaust Gas Recirculation (EGR). The engine experimental data is taken from [24]. (a) Intake manifold pressure $\left(P_{\text {man }}\right),(\mathrm{b})$ intake manifold temperature $\left(T_{\operatorname{man}}\right)$, and $(\mathrm{c})$ engine speed $(N)$. 


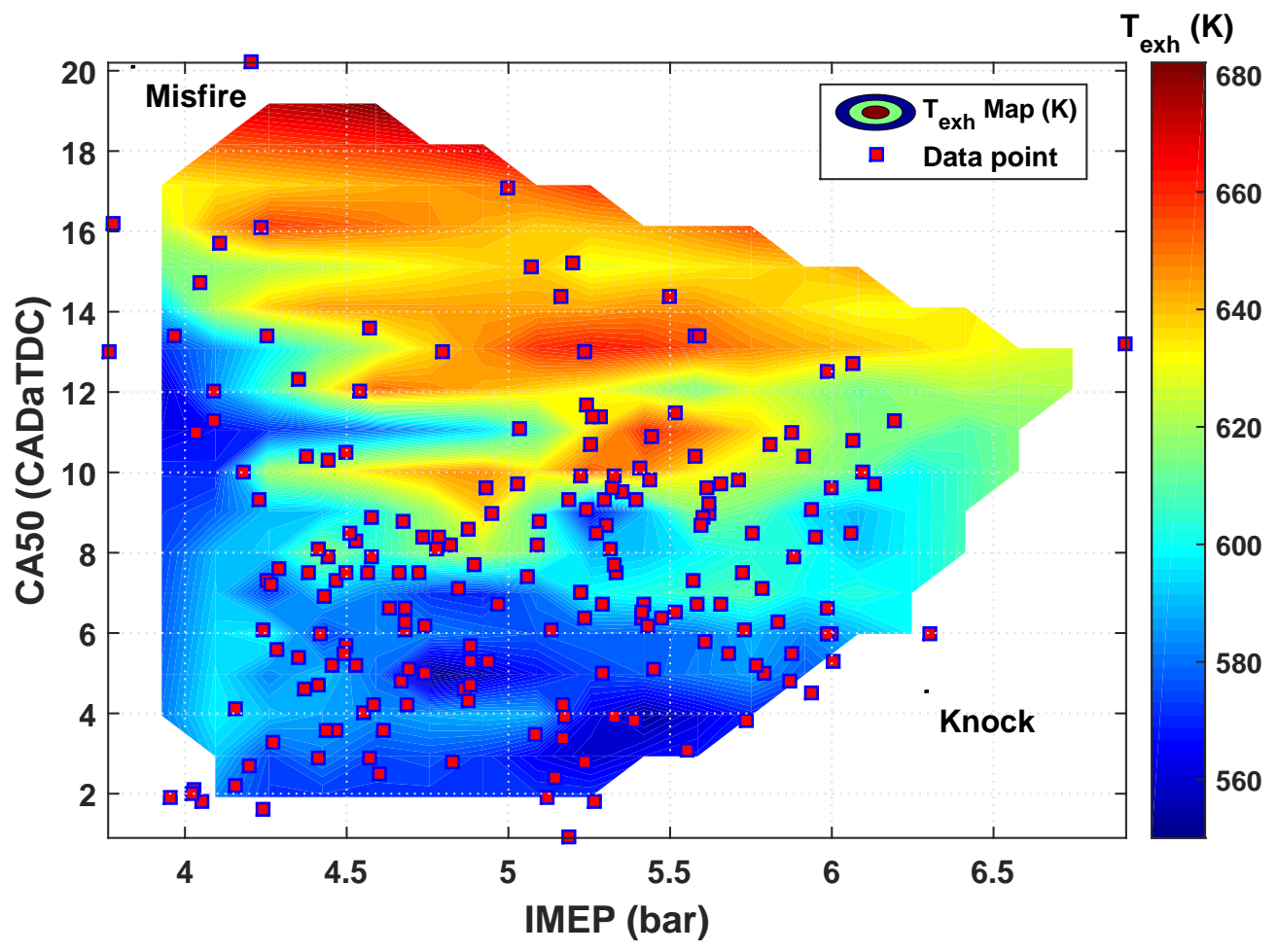

Figure 3: Exhaust gas temperature $\left(T_{e x h}\right)$ contour map with the distribution of the experimental data points in this study. 


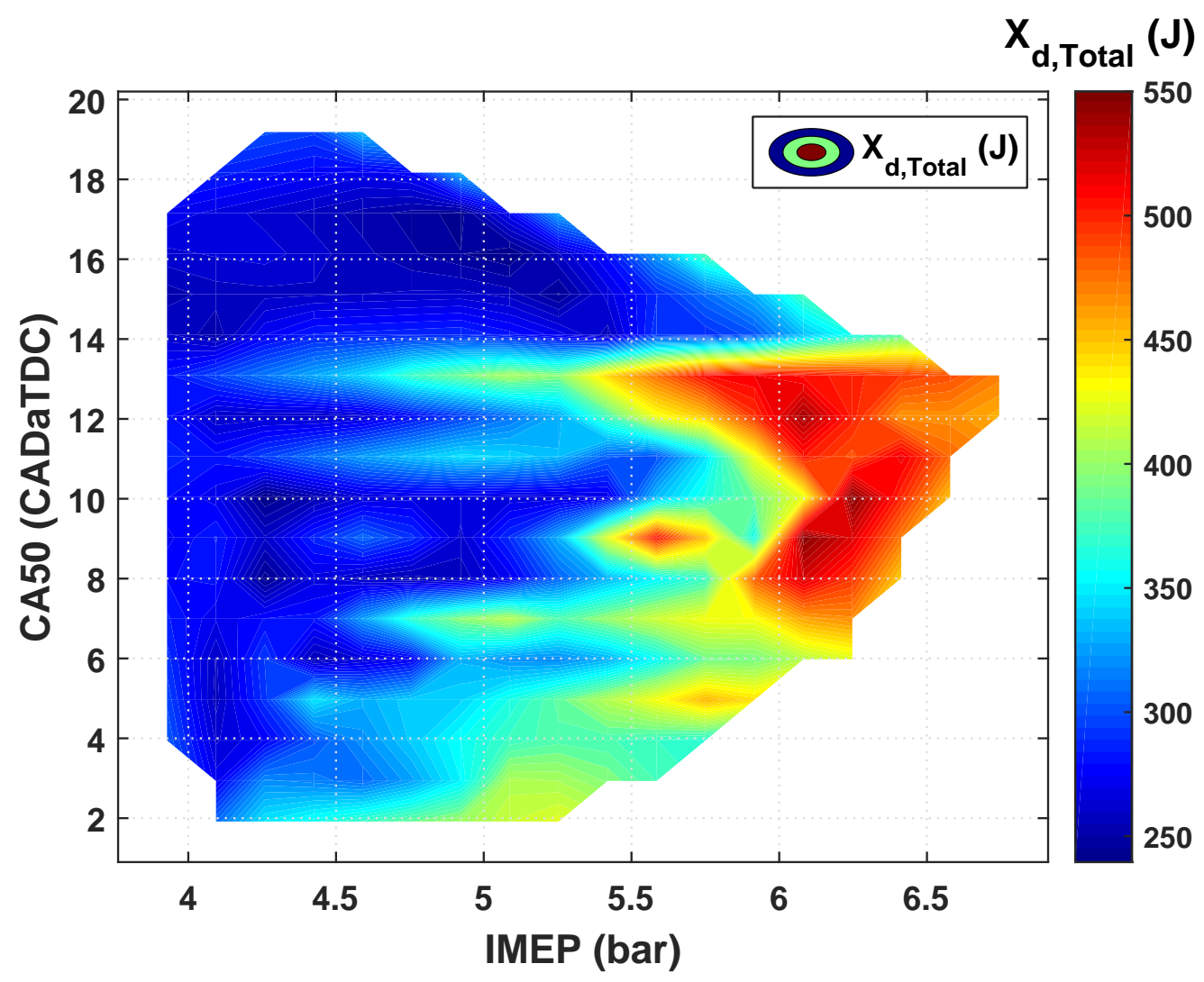

Figure 4: Combined exergy destruction and exergy loss $\left(X_{d}\right)$ contour map. This map is generated using the data points from Fig. 2 and Fig. 3 and the exergy model in this study. 
(a)

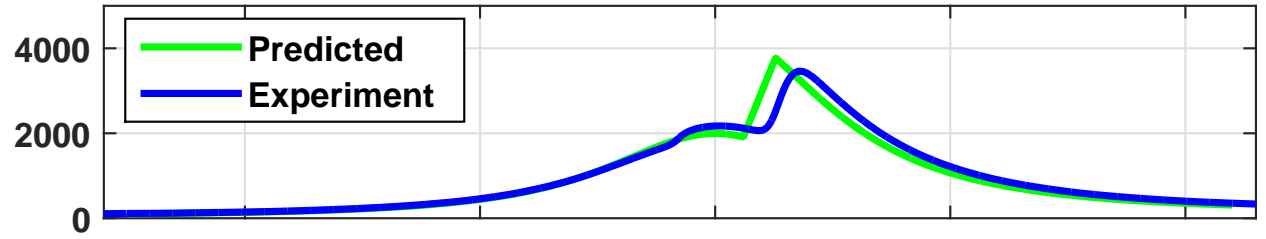

(b)

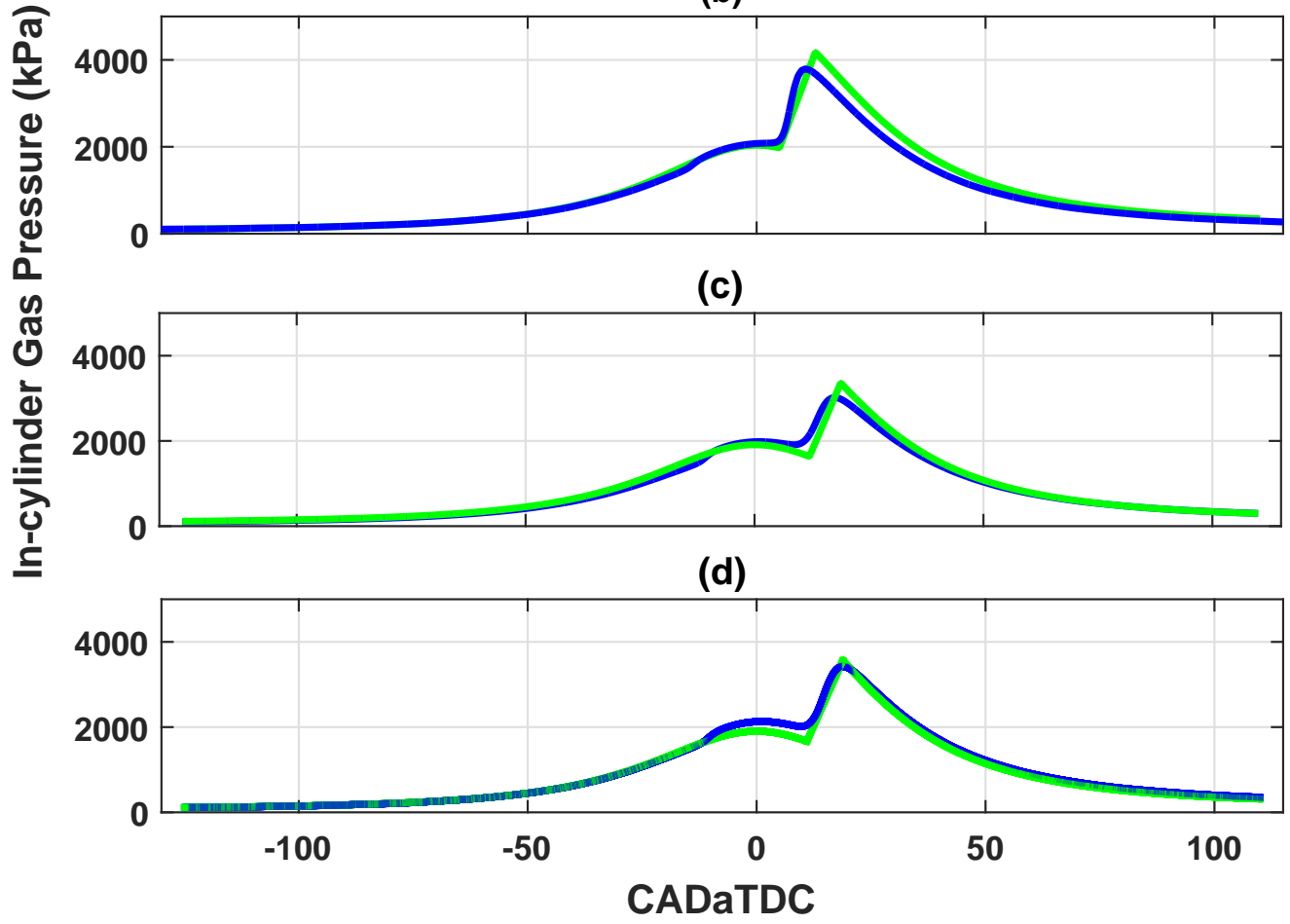

Figure 5: Experimental validation of predicted in-cylinder gas pressure for four different engine operating conditions. (a) $\phi=0.40, N=1016 \mathrm{RPM}, P_{\operatorname{man}}=100 \mathrm{kPa}, T_{\operatorname{man}}=393 \mathrm{~K}$, (b) $\phi=0.50, N=1016$ $\mathrm{RPM}, P_{\text {man }}=100 \mathrm{kPa}, T_{\text {man }}=393 \mathrm{~K}$, (c) $\phi=0.36, N=900 \mathrm{RPM}, P_{\text {man }}=110 \mathrm{kPa}, T_{\text {man }}=364 \mathrm{~K}$, (d) $\phi=0.41, N=900 \mathrm{RPM}, P_{\text {man }}=110 \mathrm{kPa}, T_{\text {man }}=366 \mathrm{~K}$. 
(a)

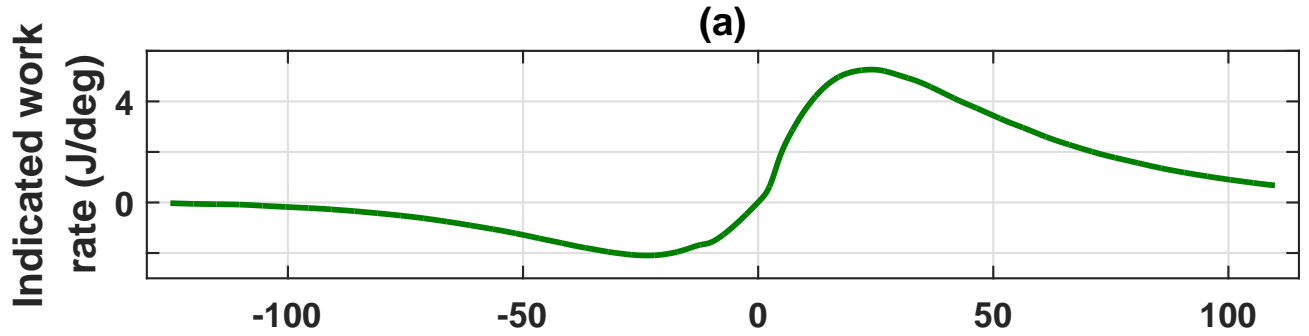

(b)

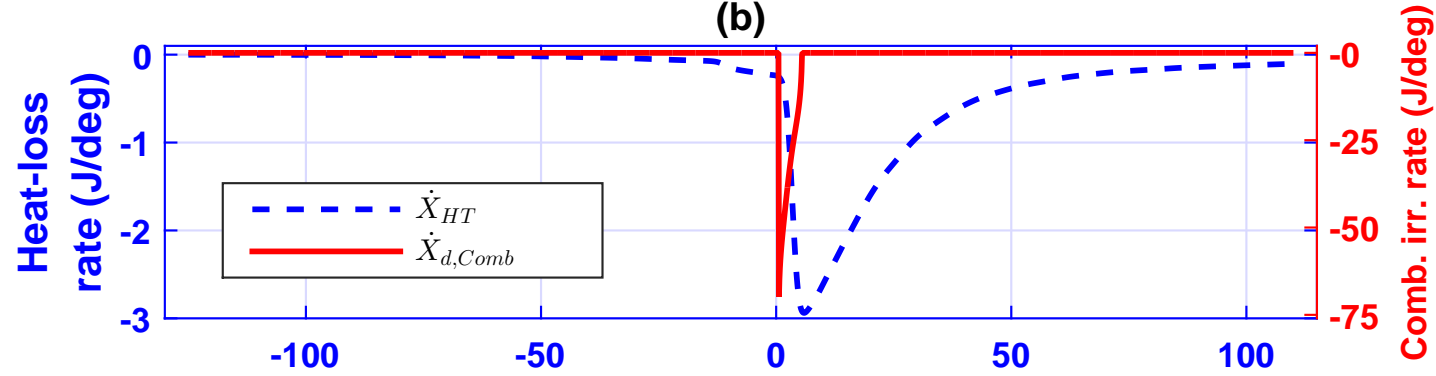

(c)

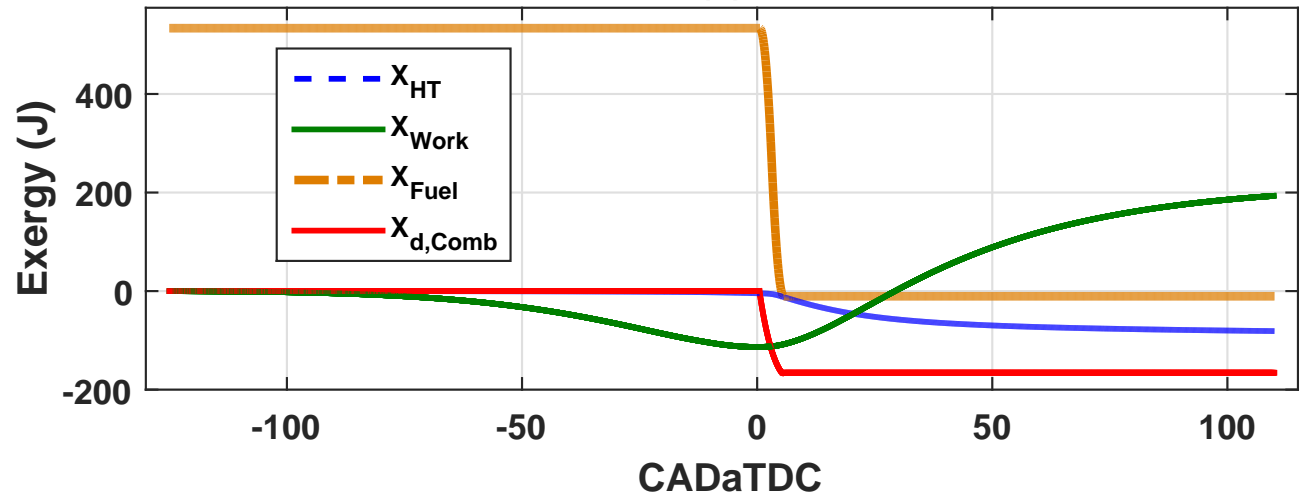

Figure 6: Crank-angle resolved exergy flow for an arbitrary engine cycle. (a) exergy work rate in the engine cycle, (b) exergy destruction rate due to combustion and exergy loss rate due to heat transfer through the cylinder walls, (c) cumulative exergy flow for the closed engine cycle. [Operating condition: $\left.\phi=0.45, N=810 R P M, O N=0, P_{\text {man }}=101 \mathrm{kPa}, T_{\text {man }}=365 \mathrm{~K}, E G R=0 \%\right]$ 


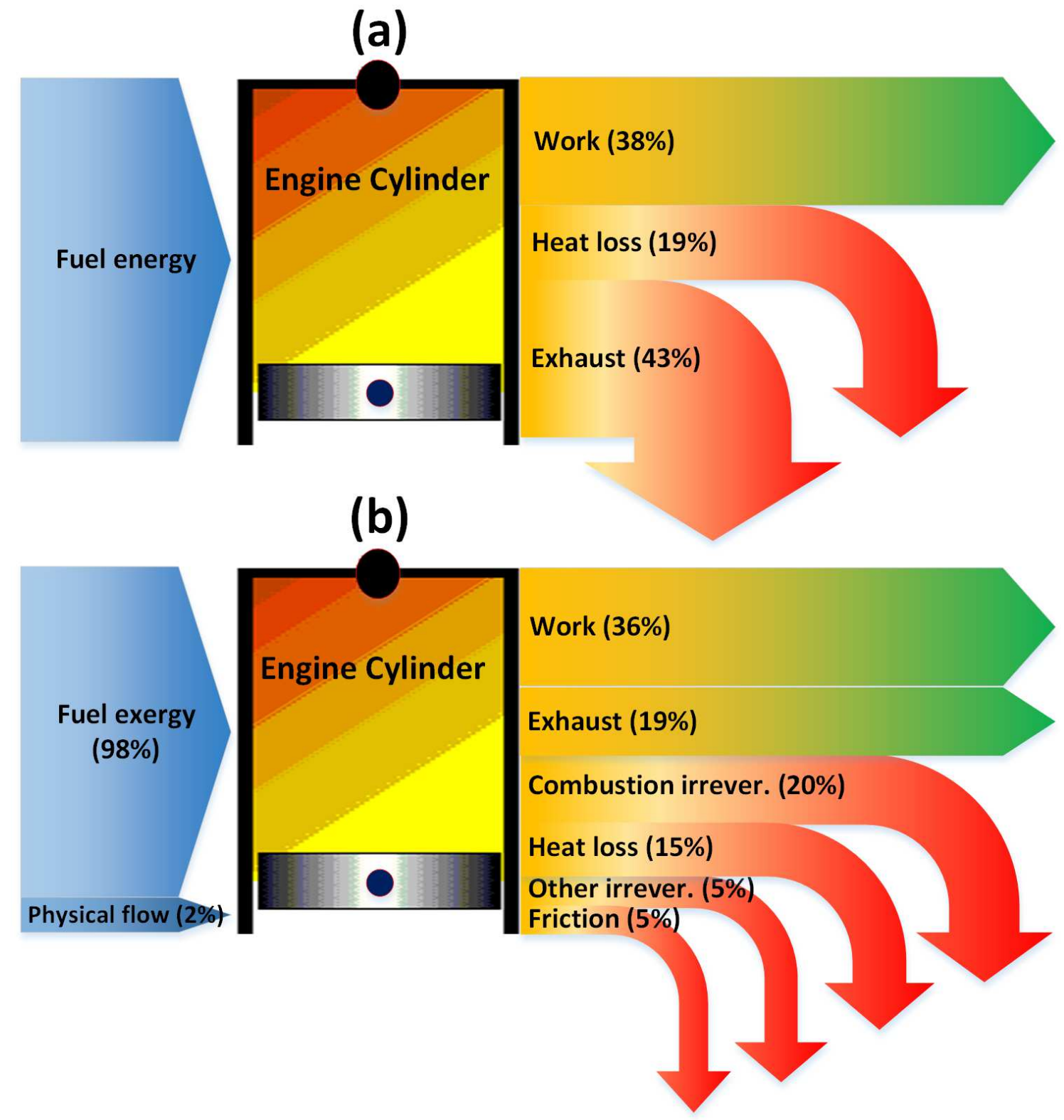

Figure 7: Energy and exergy Sankey diagram for the engine cycle in Fig. 6. Note: Since exergy of $\mathrm{n}$-Heptane fuel is $6.4 \%$ more than its LHV $[3,5]$, the work percentages are different; however, in both energy and exergy breakdowns, the values of indicated work are identical. 


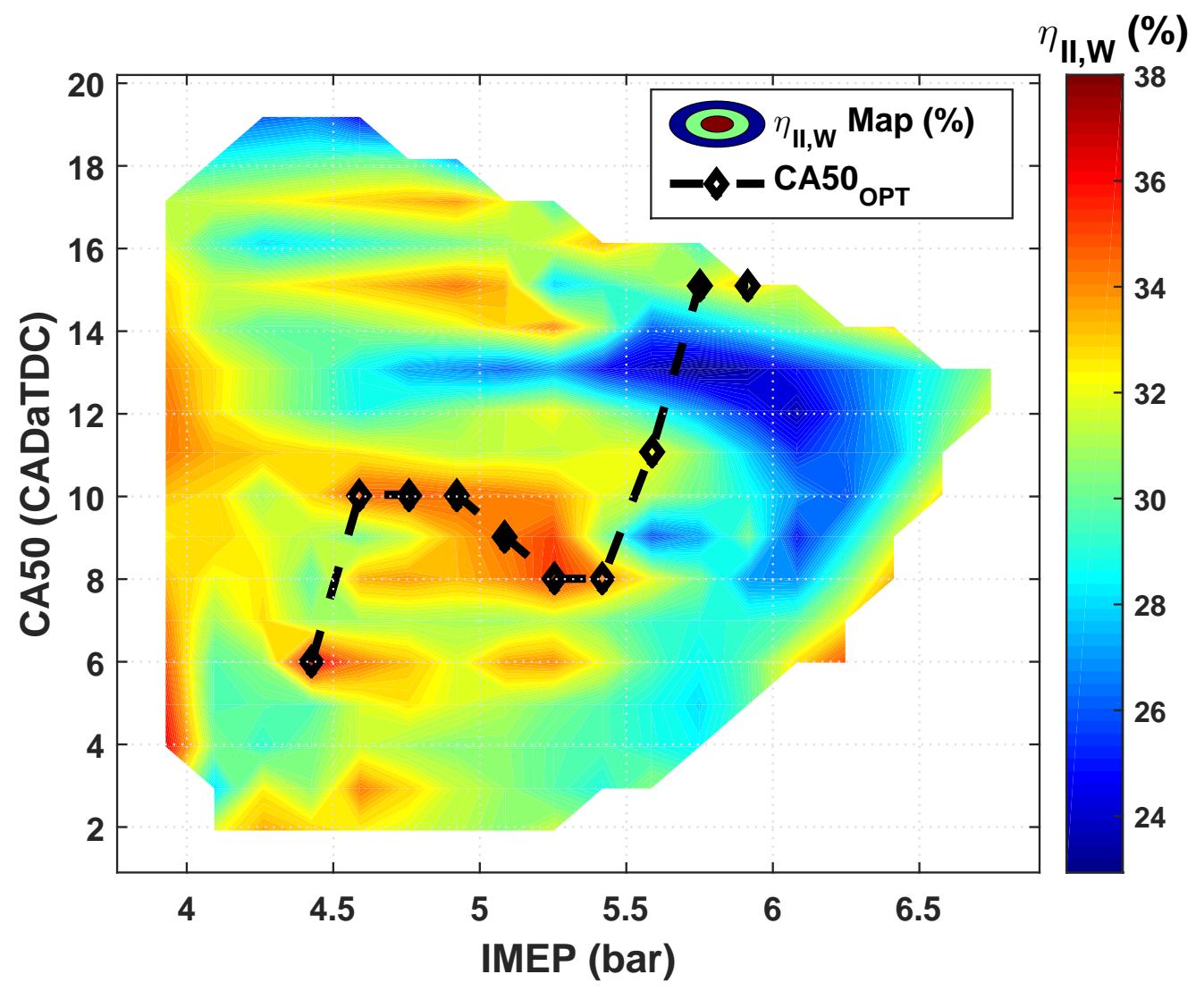

Figure 8: The SLT efficiency map $\left(\eta_{I_{W}}\right)$ with respect to the engine load (IMEP) and combustion phasing (CA50) along with the optimal CA50 trajectory. 


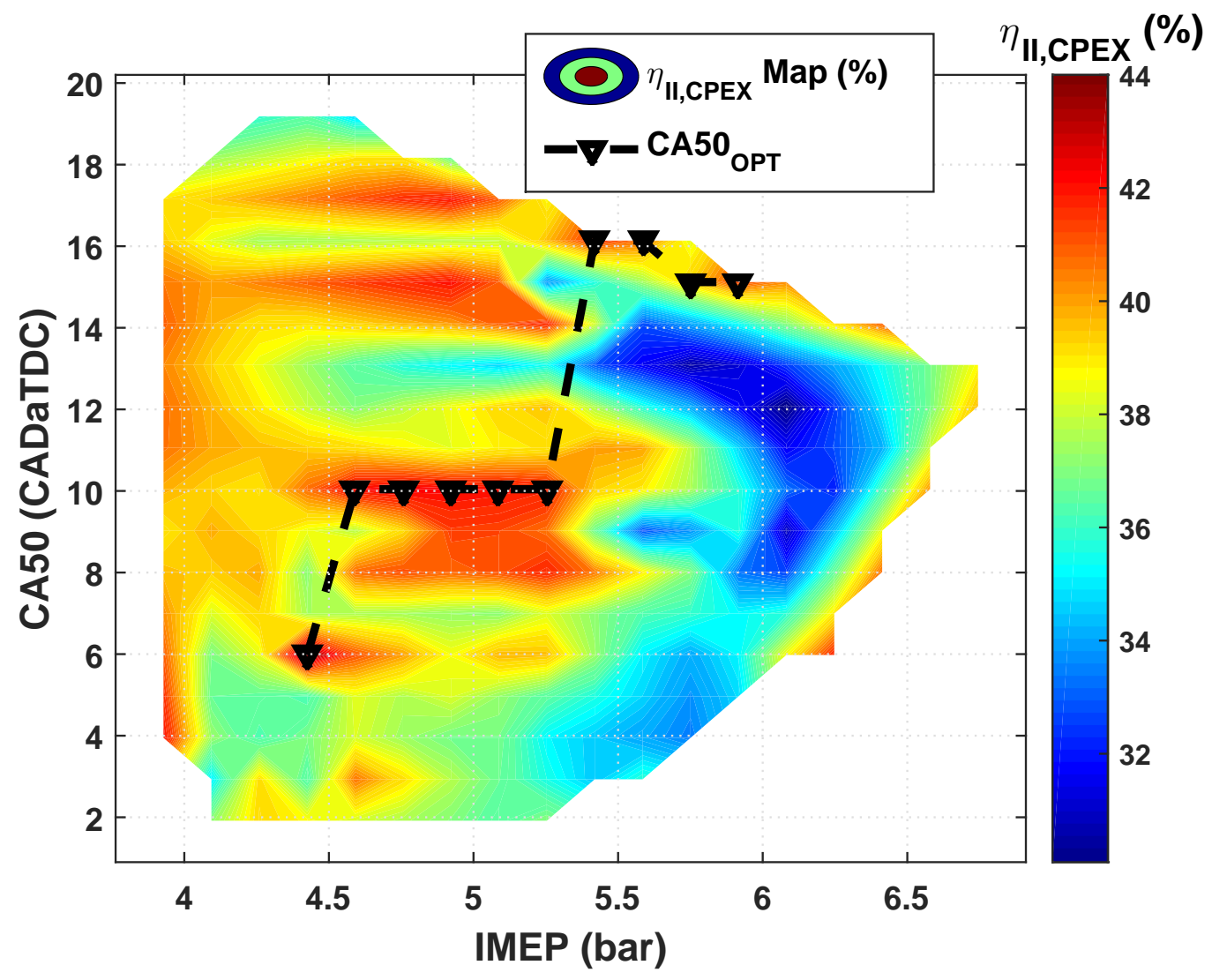

Figure 9: The SLT efficiency map for CPEX $\left(\eta_{I_{C P E X}}\right)$ with respect to IMEP and CA50 along with the optimal CA50 trajectory. 


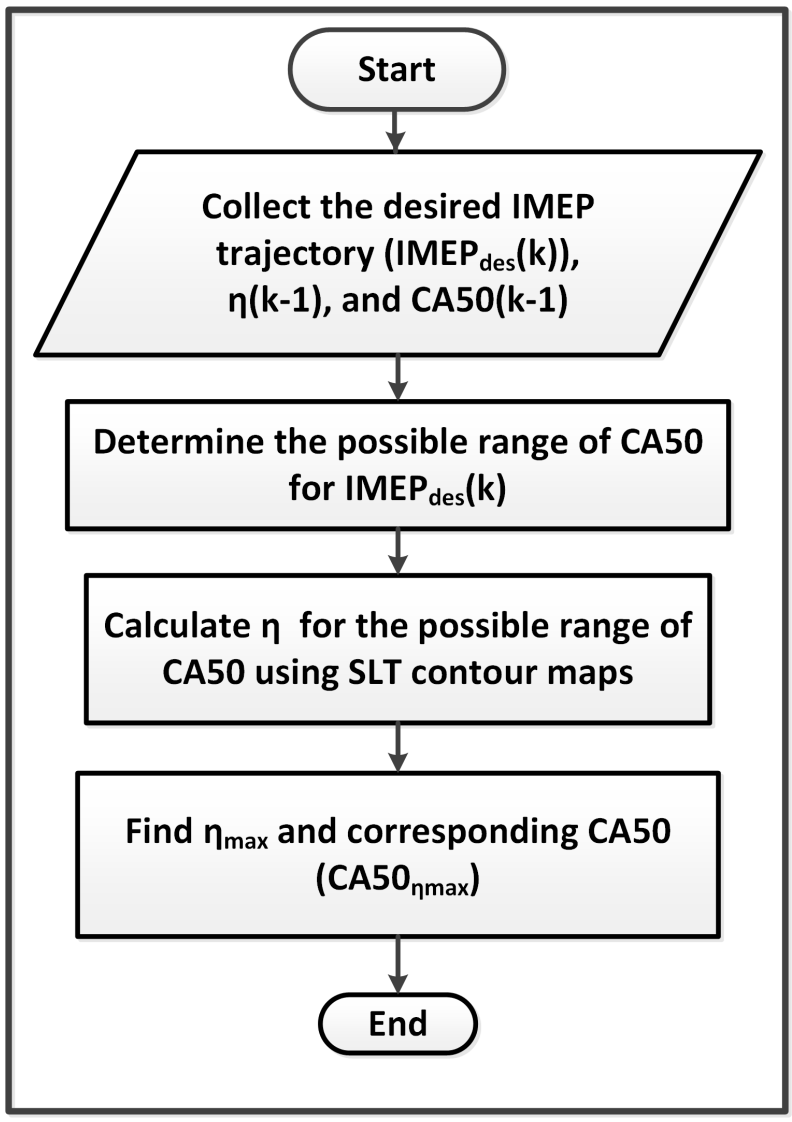

Figure 10: Proposed Exergy-based Optimal Combustion Phasing (XOCP) algorithm. XOCP is used to determine $C A 50_{O P T}$ at every given engine load. $\eta$ in the algorithm can be either $\eta_{I I, W}$ or $\eta_{I I, C P E X}$ based on the desired output. 


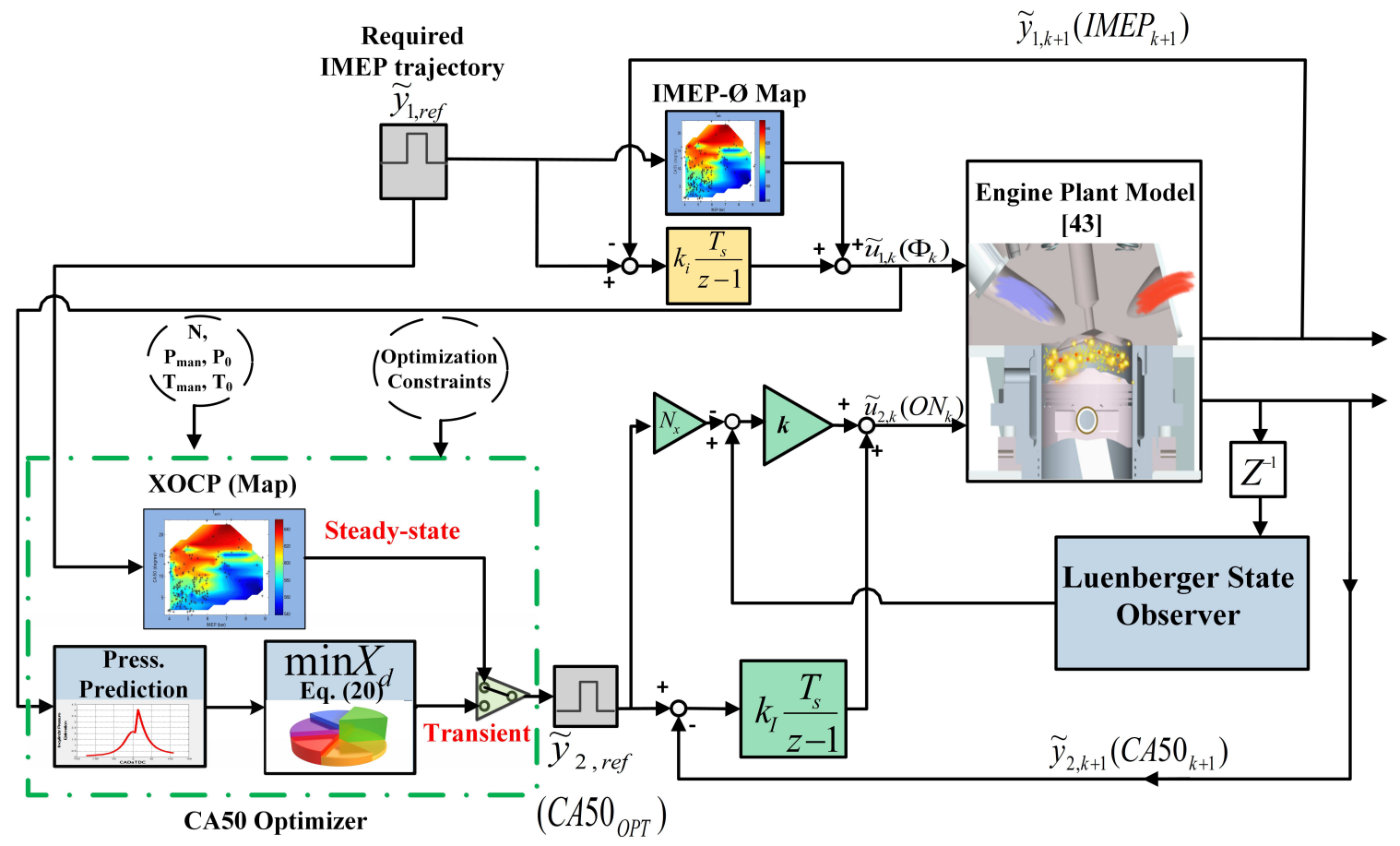

Figure 11: Structure of proposed Exergy-based Control of the IC engine (XCICE). 
(a)

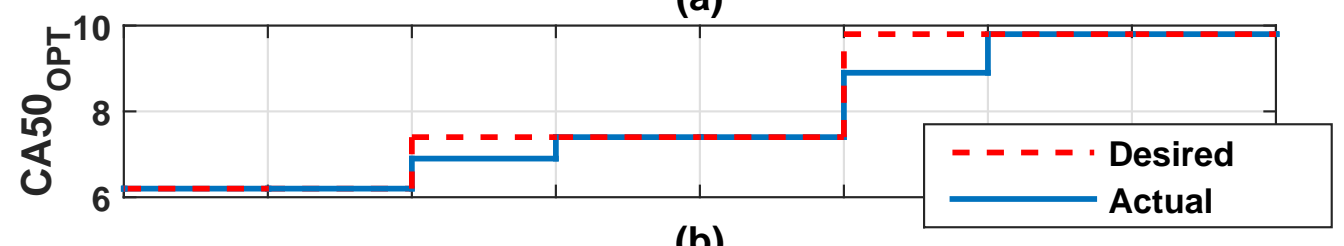

(b)

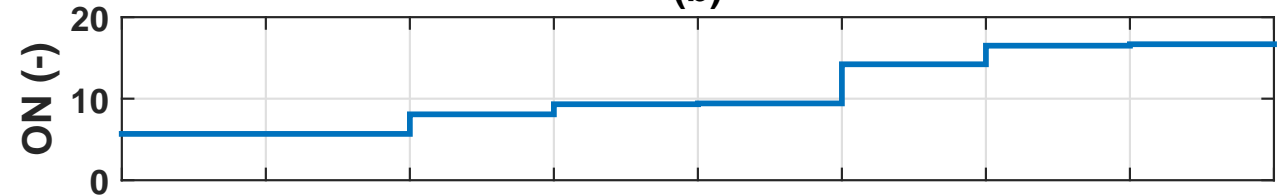

(c)

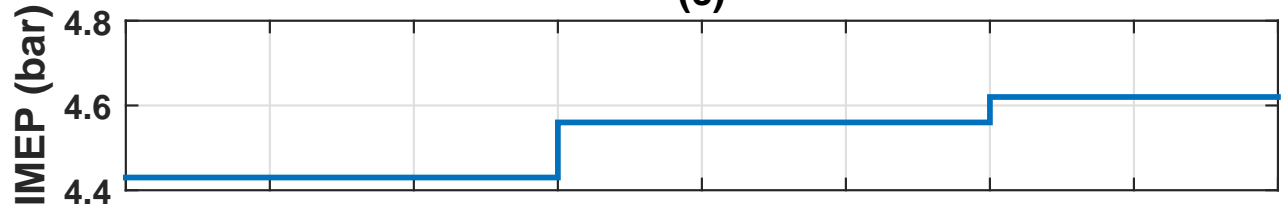

(d)
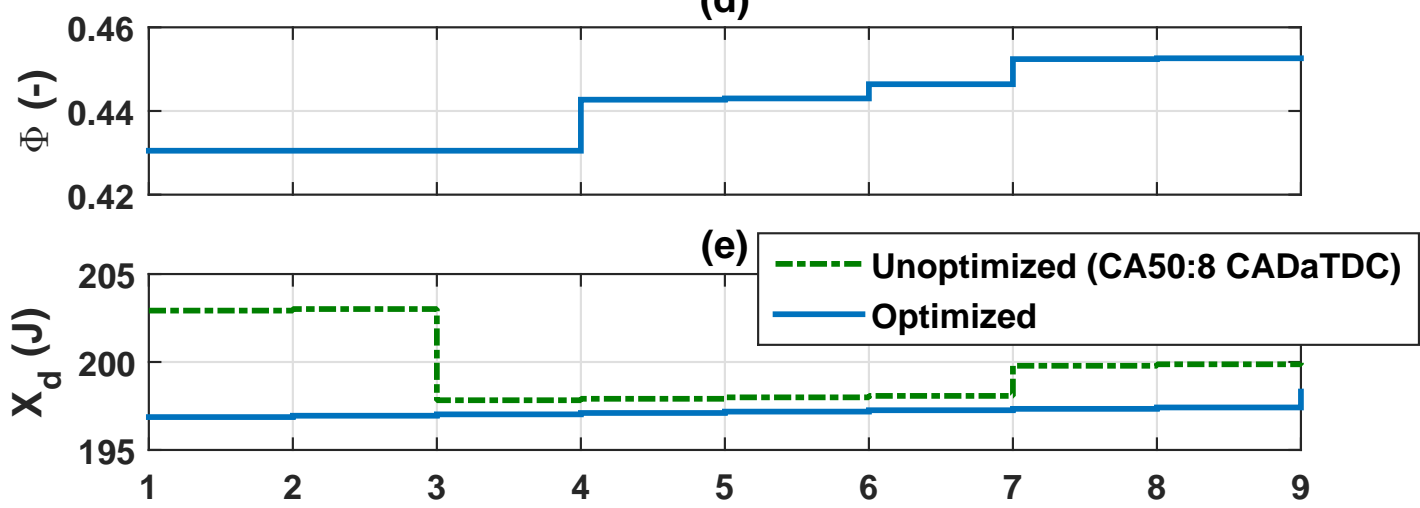

Figure 12: Results of the XCICE for tracking engine load (IMEP) and combustion phasing during transient engine operation $\left(N=800 R P M, E G R=0 \%, P_{\text {man }}=100 \mathrm{kPa}\right)$. 
(a)

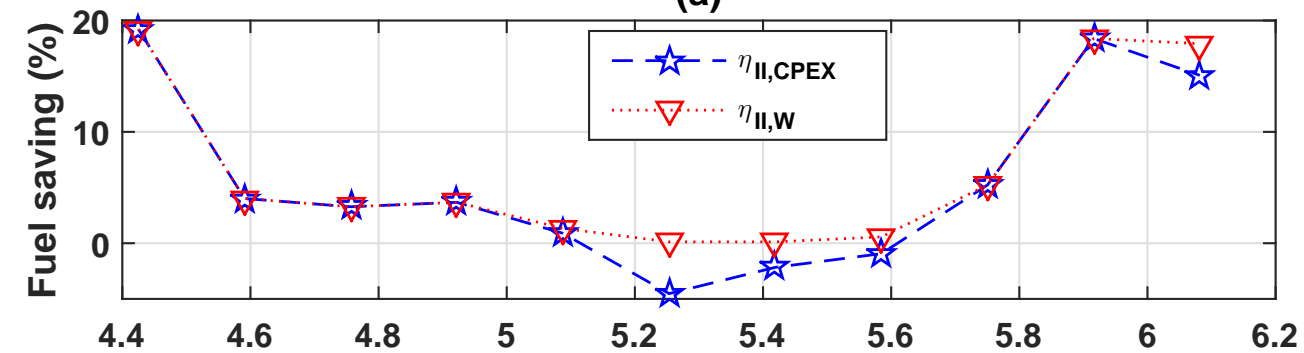

(b)

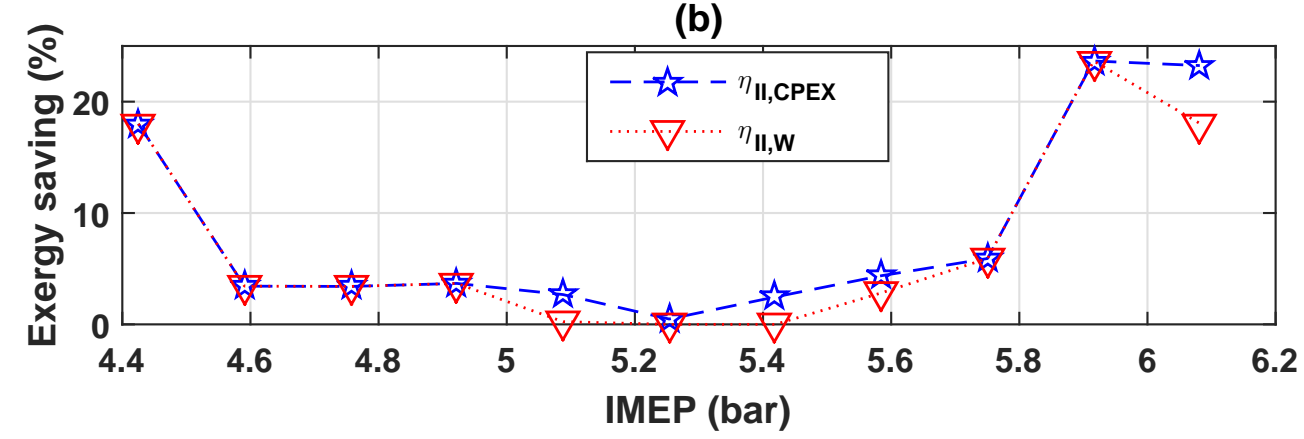

Figure 13: Fuel and exergy saving percentages compared to the unoptimized case (i.e., $8^{\circ} a T D C$ ) for the operating conditions in Fig. 8 and 9. (a) fuel saving when the trajectories on $\eta_{I I, W}$ and $\eta_{I I, C P E X}$ maps are used, (b) exergy saving $\left(X_{W o r k}+X_{E x h}\right)$ by using the trajectory shown on $\eta_{I I, W}$ and $\eta_{I I, C P E X}$ maps. To calculate the saving percentage, $\frac{x-x_{0}}{x_{0}} \times 100$ is used, where $x_{0}$ is the corresponding value for the unoptimized case. 


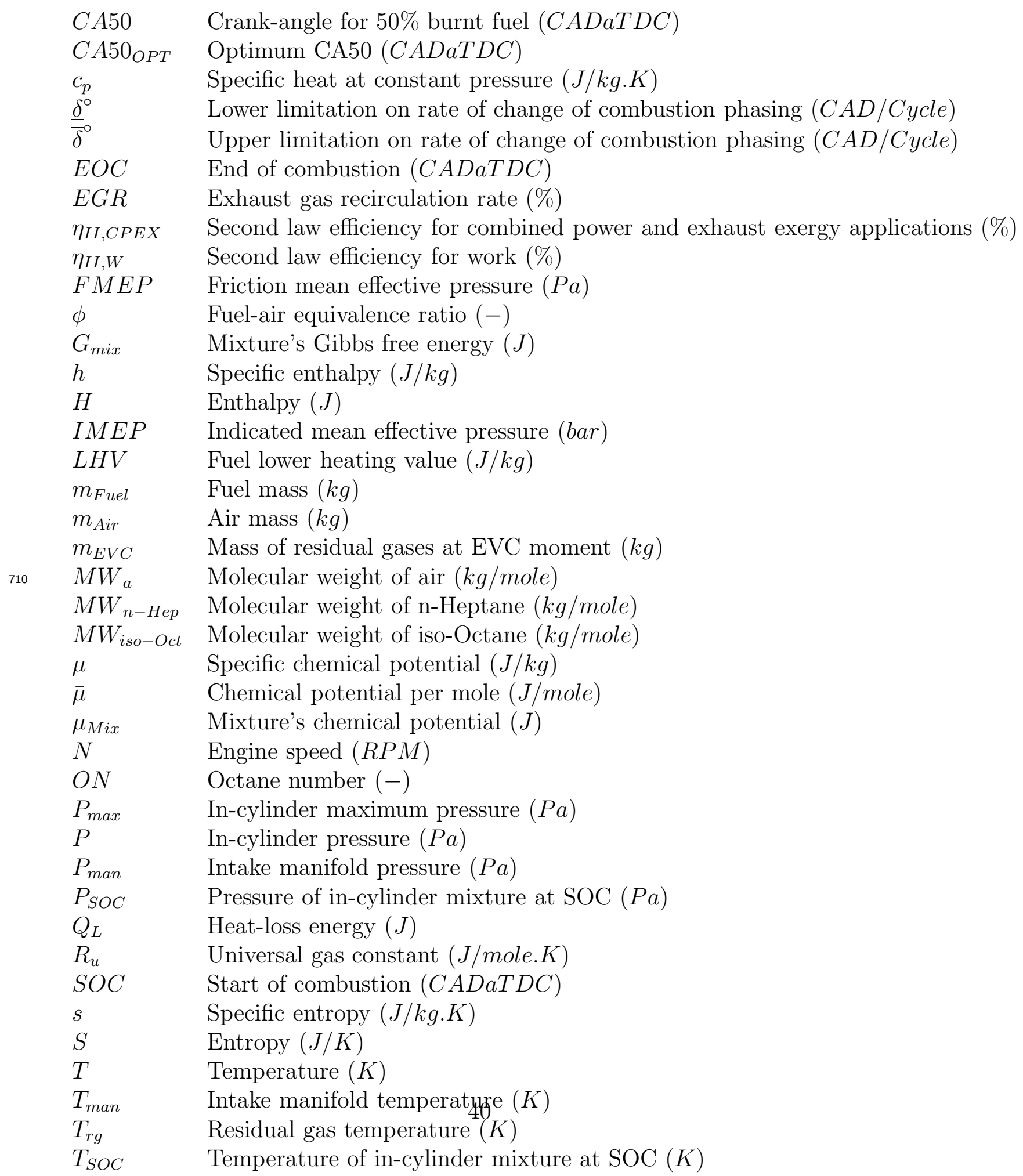




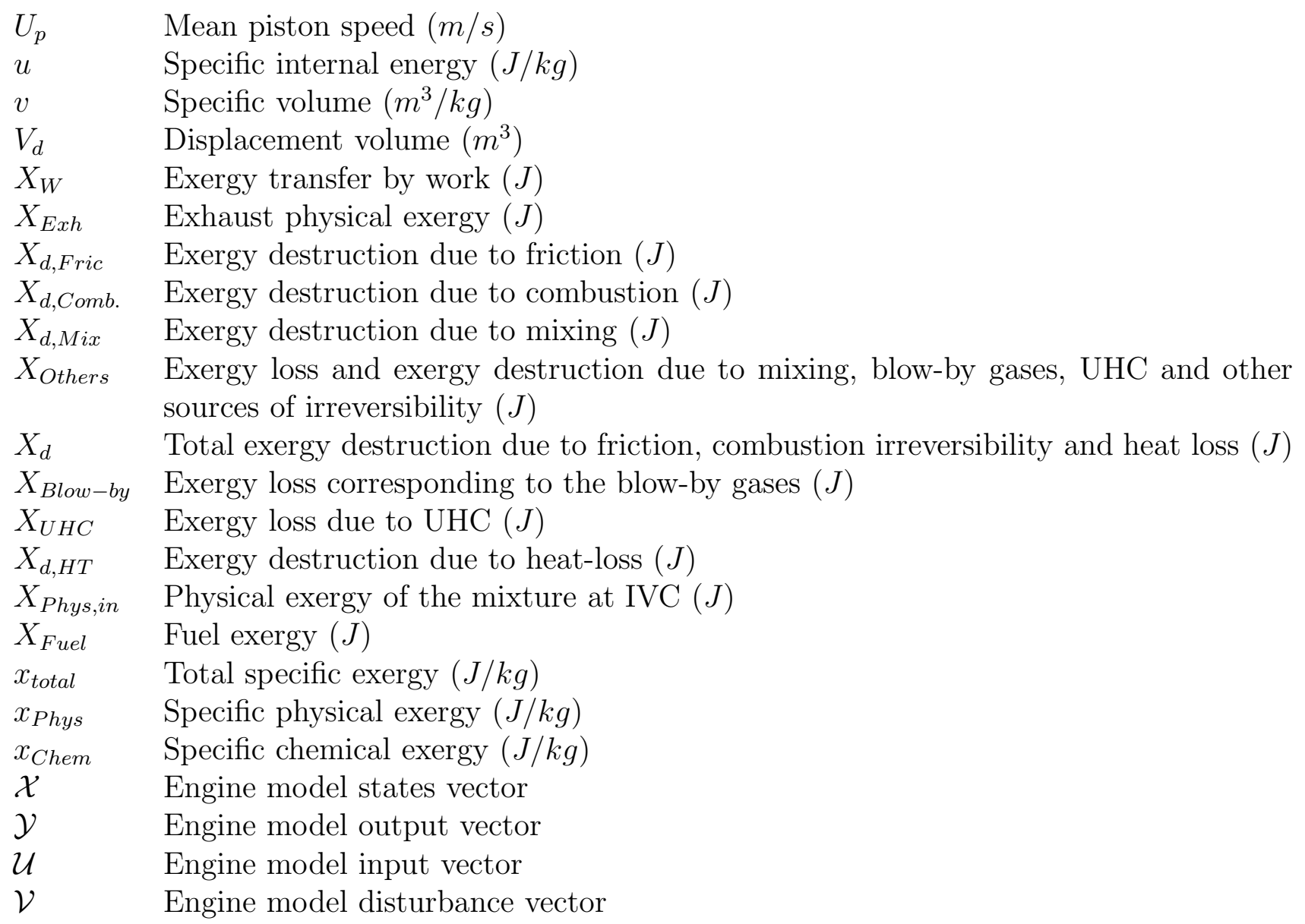


${ }_{712}$ Abbreviation

$\begin{array}{ll}a B D C & \text { After Bottom Dead Center } \\ a T D C & \text { After Top Dead Center } \\ C P E X & \text { Combined Power and Exhaust Exergy } \\ C A D & \text { Crank-Angle Degree } \\ C H P & \text { Combined Heat and Power } \\ C I & \text { Compression Ignition } \\ C R & \text { Compression Ratio } \\ E V O & \text { Exhaust Valve Opening } \\ E V C & \text { Exhaust Valve Closing } \\ F L T & \text { First Law of Thermodynamics } \\ H C C I & \text { Homogeneous Charge Compression Ignition } \\ H V A C & \text { Heating, Ventilation and Air-Conditioning } \\ I C E & \text { Internal Combustion Engine } \\ I V O & \text { Intake Valve Opening } \\ I V C & \text { Intake Valve Closing } \\ \text { 713 } & \text { Low Temperature Combustion } \\ P R F & \text { Primary Reference Fuel } \\ S L T & \text { Second Law of Thermodynamics } \\ S I & \text { Spark Ignition } \\ T E G & \text { Thermo-Electric Generator } \\ U H C & \text { Unburnt Hydrocarbon } \\ V V A & \text { Variable Valve Actuation } \\ X C I C E & \text { Exergy-based Control of Internal Combustion Engine } \\ X O C P & \text { Exergy-based Optimal Combustion Phasing } \\ & \end{array}$




\section{Highlights}

$>$ Presents a new control method to increase efficiency of internal combustion engines (ICEs)

$>$ Develops exergy model for an ICE and analyzes exergy loss/destruction in an ICE cylinder

$>$ Introduces a predictive approach to calculate exergy loss/destruction in transient operation of ICEs

$>$ Generates ICE efficiency maps based on the $2^{\text {nd }}$ Law of Thermodynamics using experimental data at 175 different operating conditions

$>$ Proposes an optimization algorithm to find the optimum combustion phasing 


\section{Dear Professor J. Yan,}

Enclosed please find a copy of the manuscript entitled "Optimal exergy-based control of internal combustion engines" for publication in Journal of Applied Energy.

The justification for publication of the manuscript is as following:

Exergy has been widely used to determine the loss mechanisms of Internal Combustion Engines (ICEs). A novel approach for Exergy-based Control of ICEs for steady-state and transient engine operations is presented in this paper.

First, an exergy model is developed for an ICE. Then, for steady-state operation of the ICE, a set of 175 experimental operating conditions is used to construct the $2^{\text {nd }}$ Law of Thermodynamics (SLT) efficiency maps. Two different SLT efficiency maps are generated depending on the applications whether work, or Combined Power and Exhaust Exergy (CPEX) is the desired output. To include transient ICE operation, a model to predict exergy loss/destruction during engine transients is developed.

An optimization algorithm is proposed to find the optimum combustion phasing to maximize the SLT efficiency. Application of the optimization algorithm is illustrated for combustion phasing control. The results are promising as the exergy-based optimal control strategy leads to an average of $6.7 \%$ fuel saving and $8.3 \%$ exergy saving compared to a commonly used approach for ICEs.

To the best of authors' knowledge, this is the first study undertaken to control steady-state and transient operation of an ICE based on exergy and SLT.

This paper builds upon our preliminary results in [23] and includes new contributions for exergybased control of ICEs. This submission is based on our original work and this manuscript is not under consideration for publication in any other journals.

The information of corresponding author:

Meysam Razmara,

PhD Candidate

910 R.L. Smith Building

Mechanical Engineering-Engineering Mechanics Department

Michigan Tech. University, Houghton, MI 49931-1295

Cell: (906) 370-5345

Email: mrazmara@mtu.edu

Sincerely,

Meysam Razmara

Mehran Bidarvatan, PhD

Mahdi Shahbakhti, PhD

Rush D. Robinett III, PhD 